\title{
Capítulo 2 \\ Otimização de Programas Paralelos com uso do OpenACC
}

\author{
Evaldo B. Costa - IC/UFRJ - ebcosta@ic.ufrj.br \\ Gabriel P. Silva - IC/UFRJ - gabriel@ic.ufrj.br
}

\section{Resumo}

Este minicurso tem por objetivo apresentar técnicas de otimização de programas paralelos que façam uso de diretivas do OpenACC. Para isso, serão utilizadas ferramentas que realizam uma análise completa de desempenho do código para identificação de regiões paralelizáveis e quais métodos podem ser aplicados. O OpenACC é um modelo de programação para computação paralela que pode ser executado em diversos tipos de arquiteturas: multicore, manycore e aceleradores. Assim, neste minicurso são avaliados os efeitos dos componentes de hardware sobre o desempenho de programas paralelos. Ressaltam-se as modificações que devem ser feitas no código para explorar com vantagem as características dos recursos computacionais, avaliando os seus respectivos impactos no desempenho de um programa.

\subsection{Arquitetura dos Aceleradores Gráficos}

As arquiteturas dos aceleradores gráficos (GPUs) são bem diferencidas das arquiteturas dos processadores convencionais. O paralelismo nos aceleradores gráficos é explorado através de um conjunto maçico de multiprocessadores de fluxo (streaming multiprocessors $(S M)$ ), executando em paralelo e de forma sincronizada trechos computacionalmente intensivos, chamados de kernels, das diversas aplicações.

Para o melhor entedimento dos aceleradores gráficos (GPUs) vamos estudar, sem perda de generalidade, a arquitetura de um tipo de acelerador gráfico desenvolvido pela NVIDIA, a arquitetura Kepler, observada na Figura 2.1.

Na Figura 2.1 verificamos que o acelerador gráfico possui uma arquitetura distinta, com diversos níveis de hierarquia de memória, algumas delas compartilhadas, outras exclusivas de cada processador de fluxo (SM). Analisamos esses e outros detalhes a seguir. 


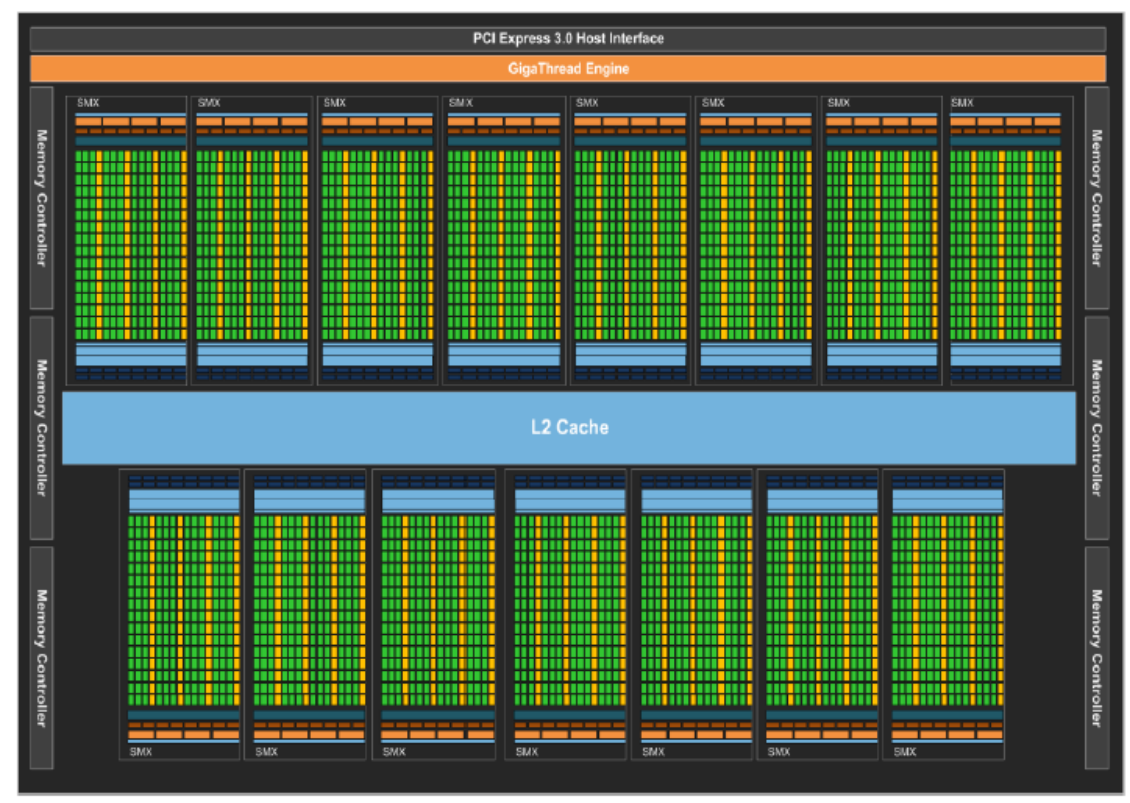

Figura 2.1: Arquitetura NVIDIA Kepler [NVIDIA 2014]

Principais características da arquitetura Kepler Cada unidade de multiprocessador de fluxo (Figura 2.2) possui 192 núcleos CUDA de precisão simples e 64 de precisão dupla, onde cada núcleo tem unidades lógicas de aritmética inteira de ponto flututante capazes de operar em modo "pipeline", incluindo operações do tipo fused multiply-add (FMA). As 32 unidades de função especial (SFU) dentro de cada SM são utilizadas para aproximar operações transcendentais como raiz quadrada, seno, cosseno e recíproco (1/x). O projeto dessa arquitetura está focado no desempenho/consumo energético, fundamental na computação de alto desempenho moderna.

O escalonador do multiprocessador de fluxo (SM) dispara as threads em grupos de 32 threads chamadas de warps. Cada SM possui quatro escalonadores de warp, permitindo um máximo de quatro warps disparadas e executadas concorrentemente. O número de registradores pode chegar até 255 registradores utilizados simultaneamente por cada thread.

Para melhorar ainda mais o desempenho, a arquitetura Kepler apresenta uma instrução de shuffle que permite às threads dentro de uma mesma warp compartilhar dados. Anteriormente, o compartilhamento de dados entre threads demandava o acesso à memória compartilhada, com operações de load e store, impactando em muito o desempenho de aplicações como a transformada de Fourier (FFT).

Outro tipo de instrução disponível são operações atômicas em memória, permitindo que as threads realizem adequadamente operações de read-modify-write, como soma, máximo, mínimo e compare-e-troque em estruturas de dados compartilhadas. Operações atômicas são amplamente utilizadas para ordenação em paralelo e para o acesso em paralelo a estruturas de dados compartilhadas sem a necessidade de travas que serializam a execução do código. 


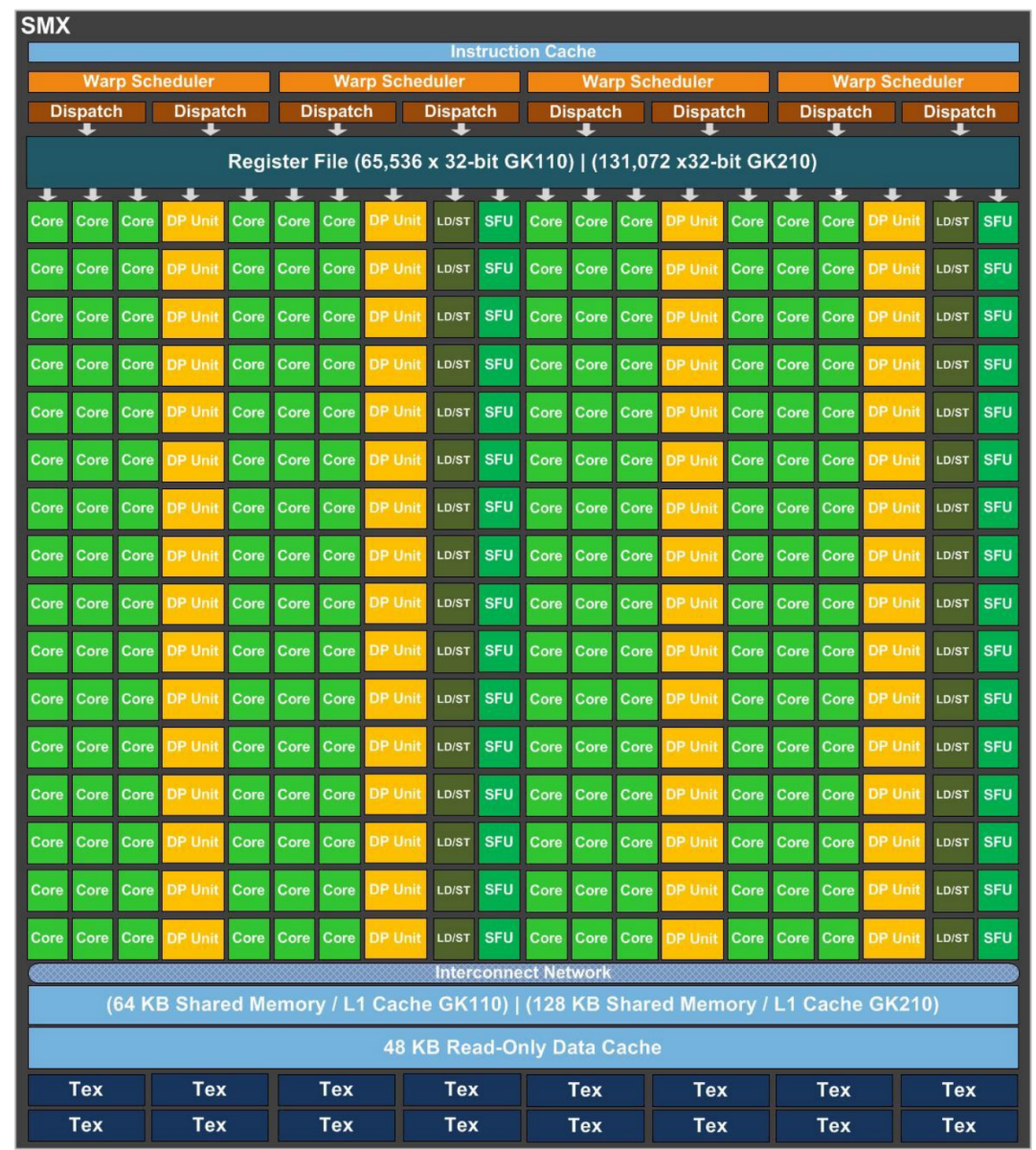

Figura 2.2: Multiprocessador de Fluxo (SM) [NVIDIA 2014]

A arquitetura de memória do acelerador está organizada em diversos níveis, possuindo uma cache L1 para cada SM, além de uma cache apenas de leitura, como visto na Figura 2.3.

A quantidade de memória de cada SM é configurável, por exemplo, a memória local (64 ou $128 \mathrm{~KB}$ ) pode ser dividida nas seguintes proporções: $75 \%$ x $25 \%, 25 \%$ x $75 \%$ ou $50 \%$ x 50\% entre uma memória compartilhada e uma cache L1.

Além da cache L1, a arquitetura Kepler introduz uma cache apenas de leitura de 48KB. $\mathrm{O}$ gerenciamento dessa cache pode ser feito automaticamente pelo compilador ou explicitamente pelo programador. O acesso a uma variável ou estrutura de dados que o programador identifica como apenas de leitura, pode ser declarada com a palavra chave const__restrict, permitindo ao compilador carregá-la na cache apenas de leitura.

Essa arquitetura possui também um cache de nivel 2 (L2) com 1,5 MB de capacidade. A cache L2 é o ponto primário de unificação de dados entre os diversos SMs, servindo operações de load, store e de textura, provendo um compartilhamento de dados eficiente e de alta velocidade. 


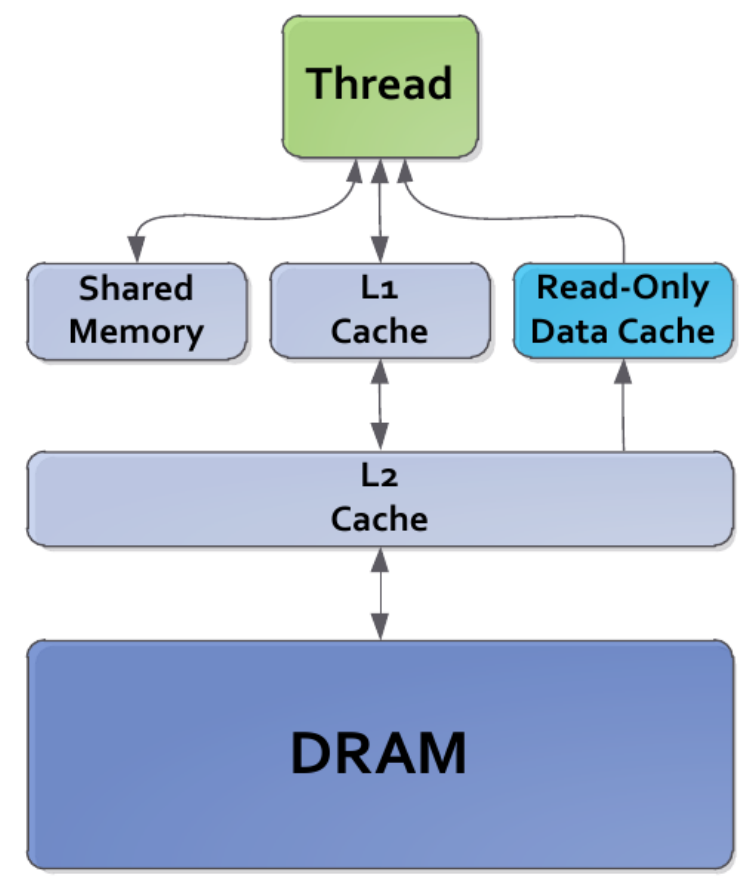

Figura 2.3: Hierarquia de Memória CUDA [NVIDIA 2014]

Algoritmos onde o endereço dos dados é conhecido previamente, tais como solucionadores de física, ray tracing e multiplicação esparsa de matrizes, se beneficiam especialmente das hierarquia de cache. Os kernels de filtro e convolução onde é necessário que diversos SMs leiam os mesmos dados, também se beneficiam dessa hierarquia.

A arquitetura possui uma série de outras facilidades como código de correção de erro, paralelismo dinâmico, gerenciamento de filas de trabalho e unidade de gerencimento de grids, que servem para melhorar o desempenho e a confiabilidade do acelerador. Maiores detalhes podem ser vistos na referência [NVIDIA 2014].

A arquitetura dos aceleradores está em constante evolução, na Tabela 2.1 apresentamos as características de alguns aceleradores NVIDIA lançados mais recentemente.

Para finalizar esta seção, gostaríamos de mostrar como se dá a execução das threads no acelerador, apresentando o modelo de programação paralela CUDA. O CUDA é uma combinação de plataforma de hardware/software que permite aos aceleradores gáficos executar programas escrito em $\mathrm{C}, \mathrm{C}++$, Fortran e outras linguagens.

Um programa CUDA invoca funções paralelas chamadas kernels, que são executados em várias threads paralelas. O programador ou compilador organiza essas threads em blocos de thread e grades de blocos de thread, conforme mostrado na Figura 2.4.

Cada thread dentro de um bloco de thread executa uma instância do kernel. Cada thread também possui IDs de thread e de bloco dentro de seu bloco de thread e grade, um contador de programa, registradores, memória privada por thread, entradas e resultados de saída. 


\begin{tabular}{|c|c|c|c|c|}
\hline $\begin{array}{l}\text { Características } \\
\text { da GPU }\end{array}$ & $\begin{array}{c}\text { NVIDIA } \\
\text { Tesla P100 }\end{array}$ & $\begin{array}{c}\text { NVIDIA } \\
\text { Tesla V100 }\end{array}$ & $\begin{array}{c}\text { NVIDIA } \\
\text { A100 }\end{array}$ & Kepler \\
\hline $\begin{array}{c}\text { GPU } \\
\text { Codename }\end{array}$ & GP100 & GV100 & GA100 & GK110 \\
\hline GPU & NVIDIA & NVIDIA & NVIDIA & NVIDIA \\
\hline Architecture & Pascal & Volta & Ampere & Kepler \\
\hline $\begin{array}{l}\text { Compute } \\
\text { Capability }\end{array}$ & 6.0 & 7.0 & 8.0 & 3.5 \\
\hline $\begin{array}{c}\text { Threads / } \\
\text { Warp }\end{array}$ & 32 & 32 & 32 & 32 \\
\hline $\begin{array}{c}\text { Max Warps / } \\
\text { SM }\end{array}$ & 64 & 64 & 64 & 64 \\
\hline $\begin{array}{c}\text { Max Threads } \\
\text { / SM }\end{array}$ & 2048 & 2048 & 2048 & 2048 \\
\hline $\begin{array}{l}\text { Max Thread } \\
\text { Blocks / SM }\end{array}$ & 32 & 32 & 32 & 16 \\
\hline $\begin{array}{c}\text { Max 32-bit } \\
\text { Registers / } \\
\text { SM }\end{array}$ & 65536 & 65536 & 65536 & 65536 \\
\hline $\begin{array}{c}\text { Max } \\
\text { Registers / } \\
\text { Block }\end{array}$ & 65536 & 65536 & 65536 & 65536 \\
\hline $\begin{array}{c}\text { Max } \\
\text { Registers / } \\
\text { Thread }\end{array}$ & 255 & 255 & 255 & 255 \\
\hline $\begin{array}{c}\text { Max Thread } \\
\text { Block Size }\end{array}$ & 1024 & 1024 & 1024 & 1024 \\
\hline $\begin{array}{c}\text { FP32 Cores / } \\
\text { SM }\end{array}$ & 64 & 64 & 64 & 192 \\
\hline $\begin{array}{l}\text { Ratio of SM } \\
\text { Registers to } \\
\text { FP32 Cores }\end{array}$ & 1024 & 1024 & 1024 & 341 \\
\hline $\begin{array}{c}\text { Shared } \\
\text { Memory } \\
\text { Size / SM }\end{array}$ & $64 \mathrm{~KB}$ & up to $96 \mathrm{~KB}$ & up to $48 \mathrm{~KB}$ & up to $48 \mathrm{~KB}$ \\
\hline
\end{tabular}

Tabela 2.1: Comparação entre Arquiteturas NVIDIA

Um bloco de thread é um conjunto de threads em execução simultânea cooperando entre si por meio de sincronização de barreira e memória compartilhada. Um bloco de thread possui um ID de bloco em sua grade. Uma grade é uma matriz de blocos de thread que executam o mesmo kernel, leem as entradas da memória global, gravam os resultados para a memória global e fazem a sincronização entre chamadas de kernel dependentes.

No modelo de programação paralela CUDA, cada thread tem um espaço de memória privado por thread usado para salvamento de registradores, chamadas de função e variáveis 

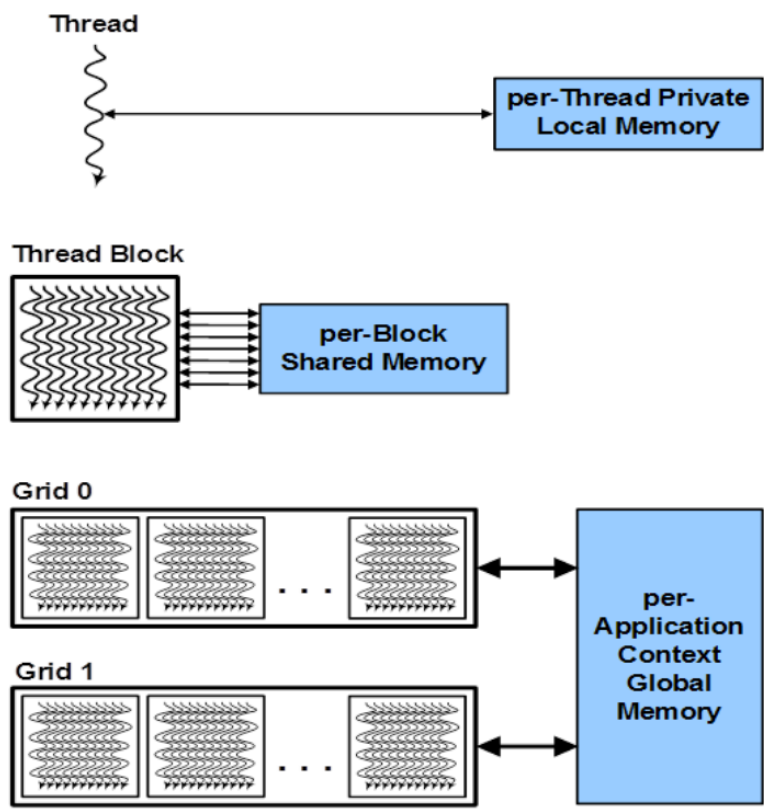

Figura 2.4: Modelo de programação CUDA [NVIDIA 2014]

de arranjo automáticas em "C". Cada bloco de thread tem um espaço de memória compartilhado por bloco usado para comunicação inter-thread, compartilhamento de dados e compartilhamento de resultados em algoritmos paralelos. Grades de blocos de thread compartilham resultados em um espaço de memória global após a sincronização global em todo o kernel.

A hierarquia de threads do CUDA é mapeada para uma hierarquia de processadores na GPU; uma GPU executa uma ou mais grades de kernel; um multiprocessador de streaming (SM) executa um ou mais blocos de threads; e os núcleos CUDA e outras unidades de execução de instruções no SM executam as threads.

O SM executa threads em grupos de 32 threads chamados warps. Embora os programadores possam ignorar os warps para uma execução funcionalmente correta, o desempenho das aplicações pode ser muito melhorado, mantendo-se as threads de um mesmo warp executando o mesmo código e realizando acessos de memória com endereços próximos.

\subsection{Memória Unificada (Unified Memory)}

As memórias da CPU e GPU são normalmente separadas, ou seja, as informações armazenadas em seus sistemas de memórias não são compartilhadas. A movimentação de dados entre os dois sistemas de memórias é realizada sempre que existe a necessidade de processamento de alguma informação.

Uma forma de solucionar esse problema é o uso de memória unificada. A memória unificada é um espaço de endereçamento único acessível tanto pela CPU como pela GPU. Com o uso dessa tecnologia de hardware/software, as aplicações alocam dados que podem ser lidos e escritos tanto pelas CPUs como pelas GPUS (Figura 2.5). 
Quando o código em execução em uma CPU ou GPU acessa dados alocados dessa maneira (CUDA managed memory), o sistema de software CUDA e/ou hardware se encarrega de migrar as páginas para a memória do processador que estiver acessando esses dados.

Destacamos que a arquitetura de GPU Pascal é a primeira com suporte de hardware para falha e migração de página de memória virtual, por meio de seu mecanismo de migração de página. As GPUs mais antigas baseadas nas arquiteturas Kepler e Maxwell também suportam uma forma mais limitada de memória unificada.

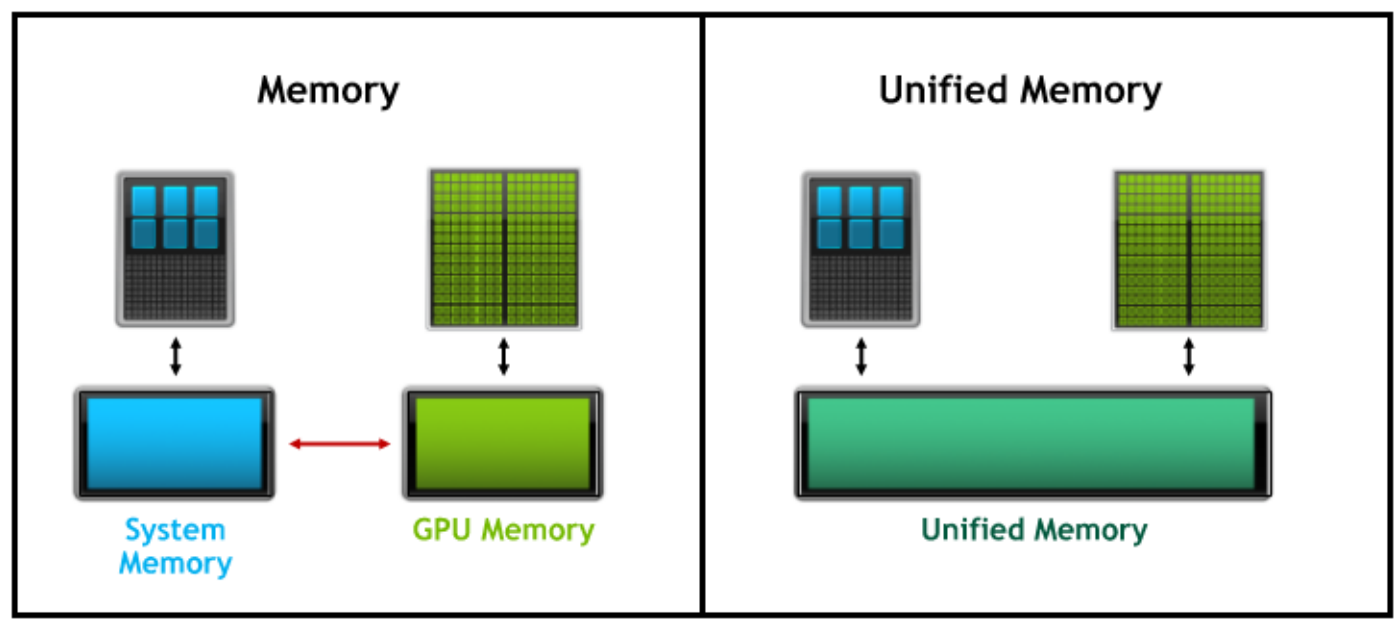

Figura 2.5: Modelo de memória tradicional e memória unificada [Harris 2017]

A alocação de memória unificada pode ser feita explicitamente em CUDA, substituindose as chamadas para a função malloc() por chamadas à função cudaMallocManaged(), uma função de alocação de memória que retorna um ponteiro acessível por qualquer processador.

Já no OpenACC essa substituição das chamadas é feita automaticamente pelo compilador. Para o uso da Memória Unificada no OpenACC com o compilador PGI, basta utilizar usar a opção -ta=tesla:managed na compilação do código do programa. Portanto, as cláusulas e diretivas de dados OpenACC não são necessárias para dados "gerenciados". Elas são essencialmente ignoradas e, de fato, podem ser omitidas.

O uso de memória gerenciada se aplica apenas aos dados alocados dinamicamente. Dados estáticos (variáveis externas e estáticas em C, módulos em Fortran, blocos comuns e variáveis salvas) e dados locais das funções são ainda manipulados pelo ambiente de execução do OpenACC.

Embora o uso da memória unificada ofereça uma grande simplificação da programação, o desempenho final é variável em função de cada aplicação e deve ser avaliado com cuidado antes de sua utilização em produção [Harris 2017].

\subsection{Conceitos de gang, worker e vector}

Como o OpenACC serve como uma linguagem para aceleradores genéricos existem três níveis de paralelismo disponíveis no OpenACC. Eles especificam o nível de paralelismo 
contidos na rotina, são chamados de gangue, trabalhador e vetor. Uma gangue é composta por um ou vários trabalhadores e corresponde a um bloco de threads em CUDA. Todos os trabalhadores de uma gangue podem compartilhar os mesmos recursos, como memória cache ou processador.

Em OpenACC, um trabalhador é um grupo de vetores. A sua dimensão vertical é igual ao número de trabalhadores e a dimensão horizontal é o tamanho do vetor. A dimensão do trabalhador se estende até a altura da gangue (bloco de threads). Cada vetor OpenACC (um elemento do arranjo iterado) é uma thread CUDA. A dimensão do vetor se dá ao longo da largura do bloco de threads.

Cada trabalhador corresponde a um número de threads igual ao tamanho do vetor. Então um trabalhador corresponde a uma warp em CUDA apenas se o vetor tiver um comprimento igual a 32; já que um trabalhador não corresponde necessariamente a uma warp. Por exemplo, um trabalhador pode corresponder a duas warps se o vetor tiver tamanho 64. A característica principal de uma warp é que todas as suas threads executam concorrentemente. Uma grade CUDA é composta de vários blocos de threads ou gangues do OpenACC, os quais podem ser organizados em uma ou duas dimensões.

Os aceleradores podem ter limitações quanto aos valores que podem ser atribuídos a esses particionamentos. Por exemplo, para GPUS da NVIDIA, as seguintes limitações existem:

- O comprimento de um vetor deve ser um múltiplo de 32 (até 1024)

- O tamanho de uma gangue é dado pelo número de trabalhadores vezes o tamanho de um vetor, não podendo ser maior que 1024.

As diretivas do OpenACC que especificam nível de paralelismo são gang, worker e vector, respectivamente para os níveis gangue, trabalhador e vetor. Essas diretivas também podem ser combinadas em um laço específico. Por exemplo, um laço gang vector pode ser particionado entre gangues, cada uma delas com 1 trabalhador implicitamente, e depois vetorizado.

A especificação OpenACC reforça que o laço mais externo deve ser um laço de uma gang, o laço paralelo mais interno deve ser um laço vector e um laço worker pode aparecer no meio. Um laço seqüencial (seq) pode aparecer em qualquer nível.

O uso dos níveis de paralelismo são aplicados na diretiva parallel loop para gerar maior ganho na execução do laço. Também podem ser usadas da diretiva kernels.

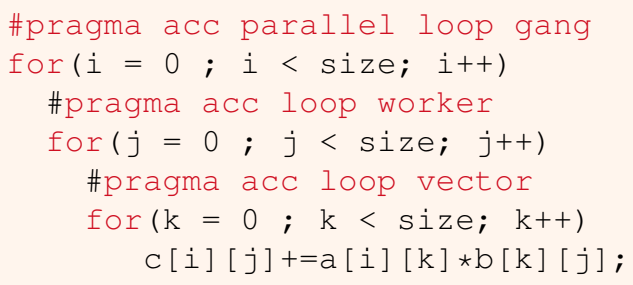

Exemplo 2.1: Cláusulas da diretiva parallel loop 
Adicionalmente, o programador pode definir esses parâmetros dentro de uma região parallel ou kernels com o uso das cláusulas num_gangs(N), num_workers(M), vector_ length(Q). Esses níveis serão empregados para todos os kernels disparados dentro da região.

\#pragma acc parallel num_gangs(expr-inteira)

\#pragma acc parallel num_workers(expr-inteira)

\#pragma acc parallel vector_length(expr-inteira)

\subsection{Movimentação de dados}

Um grande fator de impacto de desempenho no processamento paralelo é a movimentação de dados, principalmente quando se faz o processamento dos dados em lugares diferentes. Quando se usa processamento em aceleradores nem sempre é possível carregar todos os dados para o acelerador, isso ocorre em geral porque a memória da CPU é maior a dos aceleradores, embora os aceleradores tenham maior largura de banda (Figura 2.6).

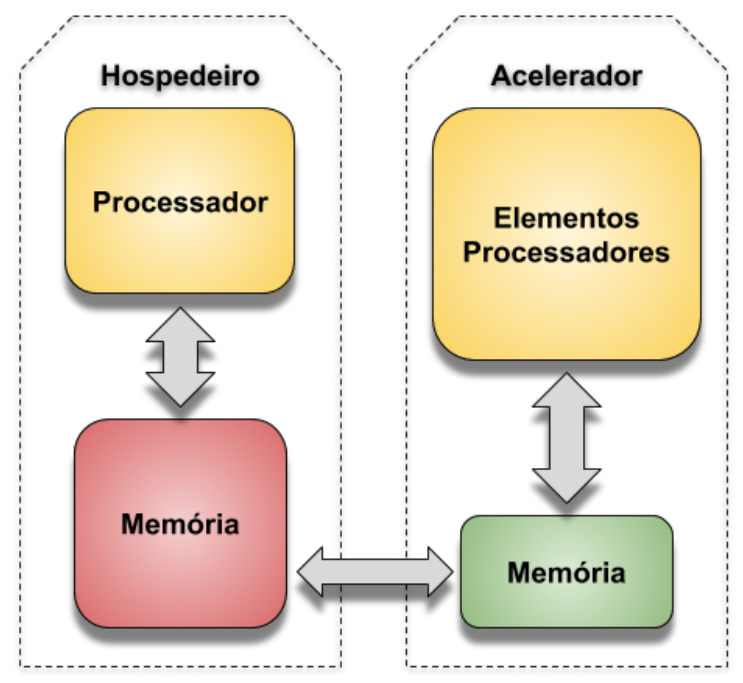

Figura 2.6: Modelo básico de movimentação de dados entre hospedeiro e o acelerador [Chen 2017]

A movimentação de dados entre o hospedeiro e o acelerador é feita através do barramento, que é lento em comparação com largura de banda de memória. Por sua vez o acelerador não pode executar o processamento dos dados até que eles estejam na sua memória local.

Para realizar a movimentação de dados entre o hospedeiro e o acelerador durante a execução do programa é necessário o uso das cláusulas de dados. As cláusulas de movimentação de dados podem ser usadas nas diretivas data, kernels ou parallel. 


\begin{tabular}{|l|l|}
\hline Cláusula & Descrição \\
\hline copy & $\begin{array}{l}\text { Cria espaço para as variáveis listadas no dispositivo, inicia as va- } \\
\text { riáveis copiando dados para o dispositivo no início da região, co- } \\
\text { pia os resultados de volta para o hospedeiro no final da região e } \\
\text { finalmente libera o espaço no dispositivo quando terminar. }\end{array}$ \\
\hline copyin & $\begin{array}{l}\text { Cria espaço para as variáveis listadas no dispositivo, inicia a va- } \\
\text { riável copiando os dados para o dispositivo no início da região } \\
\text { e libera o espaço no dispositivo quando terminar, sem copiar os } \\
\text { dados de volta para o hospedeiro. }\end{array}$ \\
\hline copyout & $\begin{array}{l}\text { Cria espaço para as variáveis listadas no dispositivo, mas não as } \\
\text { inicia. No final da região, copia os resultados de volta para o } \\
\text { hospedeiro e libera o espaço no dispositivo. }\end{array}$ \\
\hline create & $\begin{array}{l}\text { cria espaço para as variáveis listadas e as libera no final da região, } \\
\text { mas não copia nenhum dos dados de/para o dispositivo. }\end{array}$ \\
\hline present & $\begin{array}{l}\text { As variáveis listadas já estão presentes no dispositivo, portanto, } \\
\text { nenhuma outra ação precisa ser executada. Isso é usado com mais } \\
\text { frequência quando existe uma região de dados em uma rotina de } \\
\text { maior nível. }\end{array}$ \\
\hline deviceptr & $\begin{array}{l}\text { As variáveis listadas usam a memória do dispositivo que foi ge- } \\
\text { renciada fora do OpenACC, portanto as variáveis devem ser usa- } \\
\text { das no dispositivo sem qualquer conversão de endereço. Esta } \\
\text { cláusula é geralmente usada quando o OpenACC é misturado com } \\
\text { outro modelo de programação. }\end{array}$ \\
\hline
\end{tabular}

Tabela 2.2: Cláusulas da Diretiva Data

\section{\#pragma acc data [cláusula]}

\subsection{Dicas para a paralelização de laços}

A paralelização de estruturas iterativas pode disparar avisos de compilação e, às vezes, é necessário reexpressar o código do laço. Por exemplo, se o programador usa uma diretiva como kernels ou parallel, e se o compilador vê alguma dependência entre os laços, o compilador não paralelizará esse trecho do código. Expressando a mesma iteração de uma maneira diferente, pode ser possível evitar os avisos de compilação e fazer com que o compilador execute os laços em paralelo. Os exemplos de código abaixo ilustram laços que geram mensagens de erro do compilador.

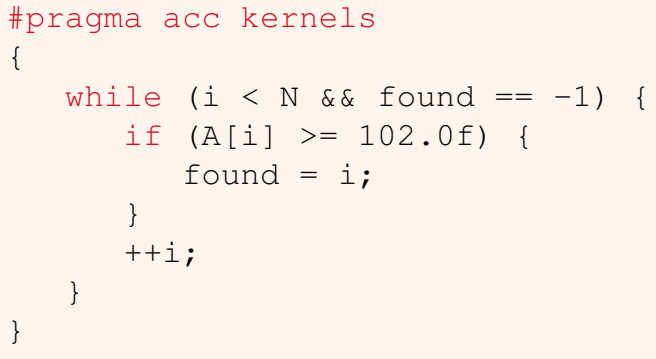


Compilando o código acima os seguintes avisos são gerados pelo compilador:

Accelerator restriction: loop has multiple exits

Accelerator region ignored

O problema aqui é que "i” poderia assumir valores diferentes quando o loop while é encerrado, dependendo se uma thread em execução encontra um valor de A [i] maior ou igual a 102,0. O valor de "i" vai variar de execução para execução e não produzirá o resultado que o programador pretendia.

Re-expressando o código com o laço "for" a seguir, com uma lógica de desvio, o compilador agora reconhece o primeiro laço como sendo paralelizável.

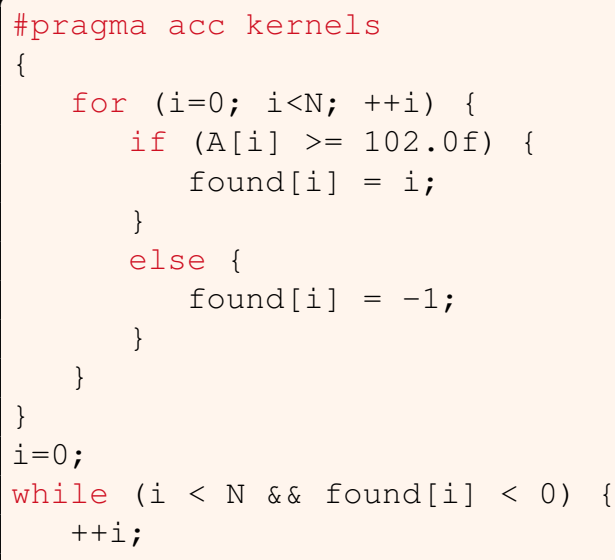

Embora esse código seja um pouco maior, com dois laços, acelerar o primeiro laço compensa a separação de um laço em dois. Normalmente, separar um laço em dois é ruim para o desempenho, mas nesse caso ao expressaros laços paralelos temos um ganho de desempenho [Murphy 2016].

Uma coisa importante a ser observada sobre a construção kernels é que o compilador analisará o código e apenas paralelizará quando estiver certo de que é seguro fazê-lo. Em alguns casos, o compilador pode não ter informações suficientes em tempo de compilação para determinar se um laço é seguro para ser paralelizado; nesse caso, isso não será feito, mesmo que o programador possa ver claramente que o laço pode ser paralelizado com segurança.

Por exemplo, no caso do código $\mathrm{C} / \mathrm{C}++$, em que as matrizes são passadas para as funções como ponteiros, o compilador nem sempre pode ser capaz de determinar que duas matrizes não compartilham a mesma área de memória, também conhecido como aliasing de ponteiros. Se o compilador não puder saber que os dois ponteiros não possuem alias, não será capaz de paralelizar um laço que acessa essas matrizes.

Uma prática recomendada para os programadores em Cé usar a palavra-chave restrict (ou o decorador _restrict em $\mathrm{C}++$ ) sempre que possível, para informar ao compilador que os ponteiros não têm alias, o que frequentemente fornecerá ao compilador informações 
suficientes para paralelizar laços que não o seriam de outra forma. Além da palavra-chave restrict, declarar variáveis constantes usando a palavra-chave const pode permitir que o compilador use memória apenas de leitura para essa variável, se essa memória existir no acelerador.

O uso de const e restrict é uma boa prática de programação em geral, pois fornece ao compilador informações adicionais que podem ser usadas na otimização do código. Um benefício adicional que a construção kernels fornece é que, se os dados forem movidos para o dispositivo para uso em laços contidos na região, esses dados permanecerão no dispositivo por toda a extensão da região ou até que sejam necessários novamente no hospedeiro dessa região. Isso significa que, se vários laços acessarem os mesmos dados, eles apenas serão copiados uma vez para o acelerador. Quando o laço paralelo é usado em dois laços subsequentes que acessam os mesmos dados, o compilador pode ou não copiar os dados entre o hospedeiro e o dispositivo entre os dois laços, o que pode resultar em menor movimentação de dados por padrão.

\subsection{Diretivas e Cláusulas Avançadas}

\subsubsection{Cláusula collapse}

A execução de um laço em OpenACC está associada ao laço imediatamente a seguir. Uma diretiva é necessária para cada laço. Isso tende a ser complicado, especialmente se vários laços devem ser tratados da mesma maneira. A cláusula collapse é útil nesse caso. $\mathrm{O}$ argumento para a cláusula collapse é um número inteiro positivo constante, que especifica quantos laços fortemente aninhados serão associados para a criar um novo laço.

Quais as vantagens em usar a cláusula collapse?

- colapsar os laços externos para permitir a criação de mais gangs.

- colapsar os laços internos para permitir comprimentos de vetor mais longos.

- colapsar todos os laços, quando for possível, para fazer as duas coisas: ter mais gangs criadas e vetores maiores.

Esta cláusula é especialmente útil quando alguns laços não tem um número total de iterações suficientemente grande para fazer uso efetivo do acelerador. A sua sintaxe é vista a seguir:

\section{\#pragma acc loop collapse(n)}

O exemplo a seguir apresenta um trecho de código com um laço com o uso desta cláusula, seguido de um laço que exemplifica o efeito do seu uso. 


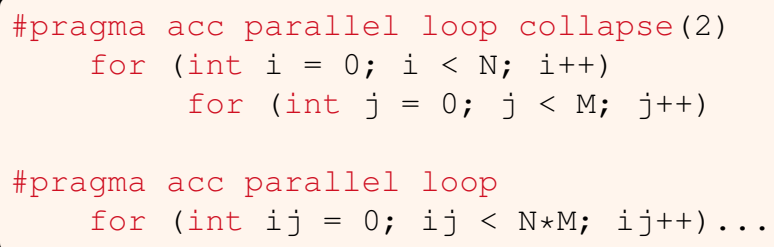

\subsubsection{Diretiva Routine}

As chamadas de função ou sub-rotina em laços paralelos podem ser problemáticas para os compiladores, pois nem sempre é possível para o compilador ver todos os laços de uma só vez. Os compiladores OpenACC 1.0 eram forçados a fazer inline de todas as rotinas chamadas em regiões paralelas ou a não paralelizar laços contendo chamadas de rotina.

O OpenACC 2.0 introduziu a diretiva routine, que instrui o compilador a criar uma versão de dispositivo da função ou sub-rotina para que possa ser chamada de uma região de dispositivo. Para leitores já familiarizados com a programação CUDA, essa funcionalidade é semelhante ao especificador da função __ device_.

Para orientar a otimização, você pode usar cláusulas para informar ao compilador se a rotina deve ser criada para paralelismo de nível de gang, work, vector ou seq (sequencial). Você pode especificar várias cláusulas para rotinas que podem ser chamadas com vários níveis de paralelismo.

Fazer isso corretamente exige que você coloque uma cláusula routine apropriada antes da definição da rotina para chamar a rotina com o nível certo de paralelismo.

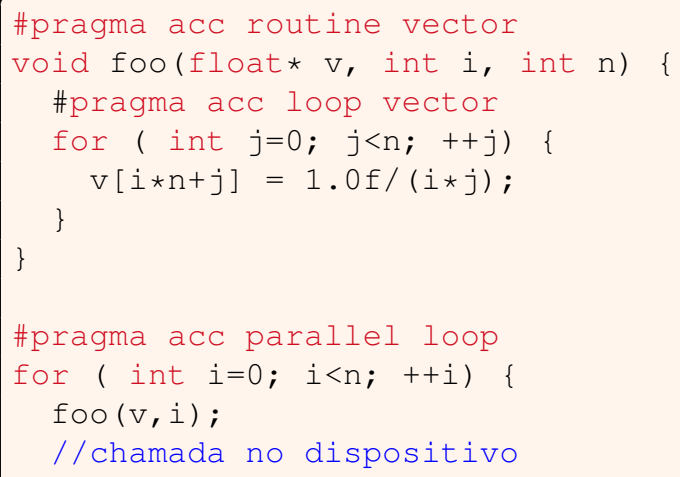

Exemplo 2.2: Diretiva Routine

Quando a rotina foo é chamada a partir do código do hospedeiro, ele será executado no hospedeiro, incrementando os valores do hospedeiro. Quando chamado de dentro de uma construção paralela do OpenACC, ela incrementará os valores do dispositivo.

Teoricamente esta diretiva permitira o uso de funções recursivas, contudo há alguns fatores que que limitam a profundidade da recursão. Por exemplo, os dispositivos NVIDIA estão limitados a 16 níveis de recursão, assim como dispositivos AMD possuem outros 
limites.

Nota: a partir da versão 14.9 do compilador PGI, uma diretiva routine sem nenhuma cláusula de nível de paralelismo (gang, worker ou vector) será tratada como se uma cláusula seq estivesse presente.

\subsubsection{Operações Atômicas}

Quando uma ou mais iterações de um laço precisam acessar um elemento na memória ao mesmo tempo, condições de corrida podem ocorrer. Por exemplo, se uma iteração do laço está modificando o valor contido em uma variável e outra está tentando ler a mesma variável em paralelo, diferentes resultados podem ocorrer dependendo de qual iteração ocorra primeiro.

Em programas seriais, os laços sequenciais garantem que a variável será modificada e lida em uma ordem previsível, mas os programas paralelos não garantem que uma iteração específica de um laço irá ocorrer antes da outra. Em casos simples, como encontrar uma soma, valor máximo ou mínimo, uma operação de redução irá garantir que o programa será executado corretamente.

Para operações mais complexas, a diretiva atomic garantirá que não haverá duas threads executando a operação nela contida simultaneamente. $\mathrm{O}$ uso da diretiva atomic às vezes é uma parte necessária do processo de paralelização para garantir a correção do código.

A diretiva atomic aceita uma das quatro cláusulas seguintes para declarar o tipo de operação contida na região:

- A operação read assegura que duas iterações de um laço não farão leituras da região ao mesmo tempo;

- A operação write garantirá que não haja duas iterações realizando escrita na região ao mesmo tempo;

- Uma operação update é uma operação de leitura e de escrita combinadas;

- Finalmente, uma operação capture executa uma atualização, mas salva o valor calculado nessa região para ser utilizada no código seguinte à região.

Se nenhuma cláusula for definida, uma operação update é assumida.

Um histograma é uma técnica comum para contar quantas vezes os valores ocorrem em um conjunto de entrada de acordo com o seu valor. O código do exemplo abaixo percorre uma série de números inteiros de um intervalo conhecido e conta o total de ocorrências de cada número nesse intervalo. Como cada número no intervalo pode ocorrer várias vezes, precisamos garantir que cada elemento no vetor de histograma seja atualizado atomicamente. $\mathrm{O}$ código abaixo demonstra usando a diretiva atomic para gerar um histograma. 


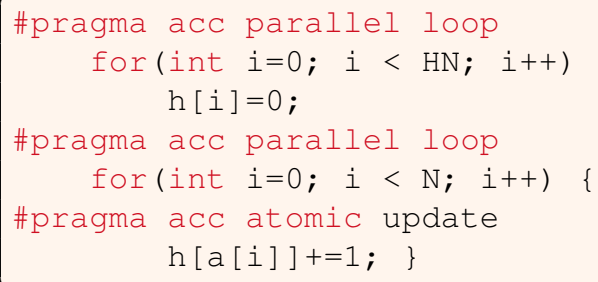

Exemplo 2.3: Diretiva atomic

Observe que as atualizações no vetor do histograma $h$ são executadas atomicamente. Como estamos incrementando o valor do elemento de um vetor, uma operação update é usada para ler o valor, modificá-lo e gravá-lo novamente.

\subsubsection{Cláusula tile}

É a adição da cláusula tile à diretiva acc loop. Com a cláusula tile é possível otimizar o laço através da operação de blocos menores para explorar o acesso aos dados. Considere o seguinte exemplo de transposição de matriz.

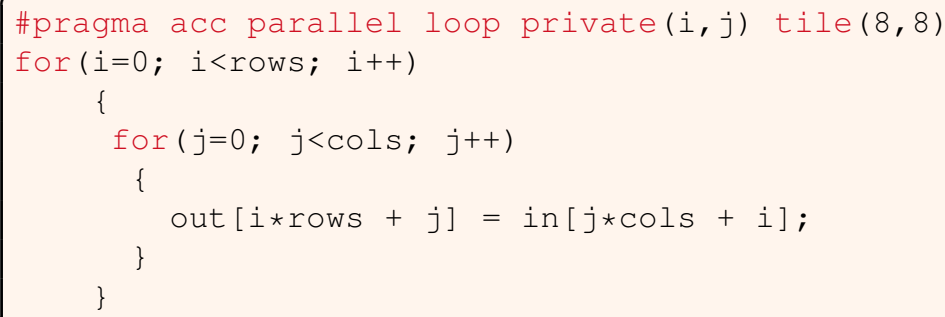

Exemplo 2.4: Cláusula tile

Ao adicionar a cláusula tile $(8,8)$ ao laço paralelo, serão criados automaticamente pelo compilador dois laços adicionais que funcionam em um chunk 8x8 (tile) da matriz antes de passar para o próximo chunk. Com isso o compilador faz a otimização dentro do bloco, com o objetivo de obter melhor desempenho. Embora uma transposição de matriz não tenha muita reutilização de dados, outros algoritmos podem ter uma melhora significativa no desempenho, explorando a localidade e a reutilização de dados nos laços disponíveis.

\subsection{Cláusulas device_type e vector_length}

O OpenACC permite que os programadores consigam otimizar suas diretrizes para aceleradores específicos com o uso da cláusula device_type, com isso é possível obter melhores desempenhos. Com o OpenACC 1.0, diretivas de pré-processador eram necessárias para ajustar as diretivas para uso em aceleradores específicos. Além de dificultar a manutenção do código, devido à duplicação de diretivas, isso significa que é impossível oferecer suporte a vários tipos de dispositivos no mesmo executável. Já com a versão do OpenACC 2.0 ele permite que determinadas cláusulas sejam fornecidas especificamente para determinadas arquiteturas.

Apenas as cláusulas async, wait, num_gangs, num_workers e vector_length podem 
aparecer em seguida a uma cláusula device_type.

\section{\#pragma acc loop device_type(lista-tipo-dispositivo)}

Um exemplo de cláusula que pode ser utilizada em associação com a cláusula device_type é a vector_length, que é utilizada para especificar o tamanho do vetor que será usado em um laço paralelo (com a diretiva parallel loop).

No Exemplo 2.5 é especificado um comprimento difernte de vetor, dependendo do tipo de acelerador que será usado. Nesse exemplo, se o laço for utilizar um acelerador NVIDIA, o compilador utilizará um comprimento vetorial de 256; se for utilizar um acelerador Radeon, o compilador usa um comprimento de vetor de 512; e para qualquer outro acelerador que não seja especificado será usado comprimento vetorial de 64. Ambas as cláusulas podem ser utilizadas em conjunto com as demais cláusulas do OpenACC.

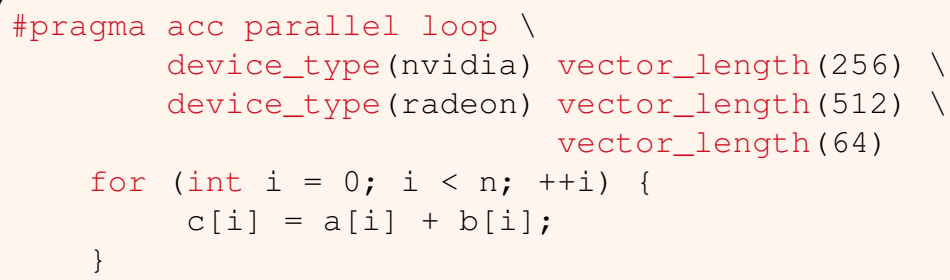

Exemplo 2.5: Cláusula tile

\subsection{PGI Profiler}

O PGI Profiler é uma ferramenta utilizada para analisar o desempenho de programas paralelos escritos com OpenMP, MPI, OpenACC ou CUDA. O PGI Profiler permite a visualização e otimização do desempenho de uma aplicação através da análise da linha do tempo de execução da aplicação. Com isso é possível identificar regiões de gargalos que podem ser otimizadas, eliminando ou reduzindo esses gargalos para alcançar um melhor desempenho.

Para iniciar a análise da execução de uma aplicação é utilizamos primeiro o comando pgprof. Esse comando gera um arquivo de saída com as informações de uso dos recursos computacionais em todos os trechos da aplicação. Não é necessário nenhum tipo de alteração no código para criar o arquivo de saída, entretanto, existem alguns parâmetros do compilador PGI que podem ser usados para coletar mais informações de uso dos recursos. Veja mais detalhes na referência [PGI 2019].

Após a execução do comando pgprof, a análise da aplicação pode ser realizada com o uso de comandos em modo terminal ou gráfico. Para executar no modo terminal, use o comando:

\section{\# pgprof [parametro] [aplicação]}

Em modo gráfico executar somente o comando:

\section{\# pgprof}




\subsection{Exemplos}

Após a introdução dos conceitos e das principais diretivas que serão usadas neste minicurso, veremos alguns exemplos de aplicações dessas diretivas, como se comportam e quais as melhores opções do seu uso para melhorar o desempenho.

\subsubsection{Cálculo de Pi}

Iniciaremos com o exemplo o cálculo do número Pi. Em computação existem diversos algoritmos que podem ser utilizados para o cálculo aproximado do Pi. No Exemplo 2.6 é apresentada uma implementação do cálculo de Pi utilizando uma integral cujo resultado é aproximado com uso do método do trapézio.

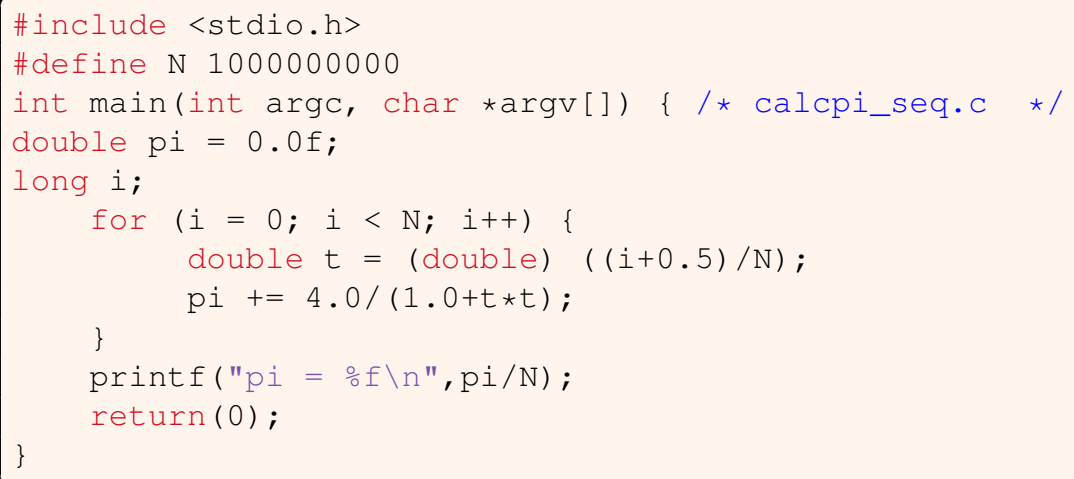

Exemplo 2.6: Cálculo de Pi sequencial

Para execução do código em paralelo no acelerador podem ser utilizadas as diretivas kernels ou parallel do OpenACC. Para o uso da diretiva kernels, adicionaremos a linha: \#pragma acc kernels.

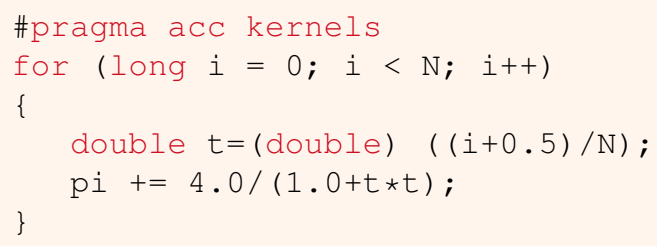

Para o uso da diretiva parallel adicionaremos, sempre antes do laço, a linha:

\#pragma acc parallel loop reduction(+: pi)

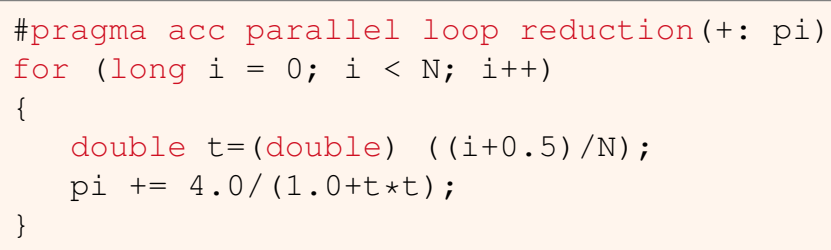


Durante a compilação do código é possível observar o resultado do uso dessas diretivas (Figura 2.7).

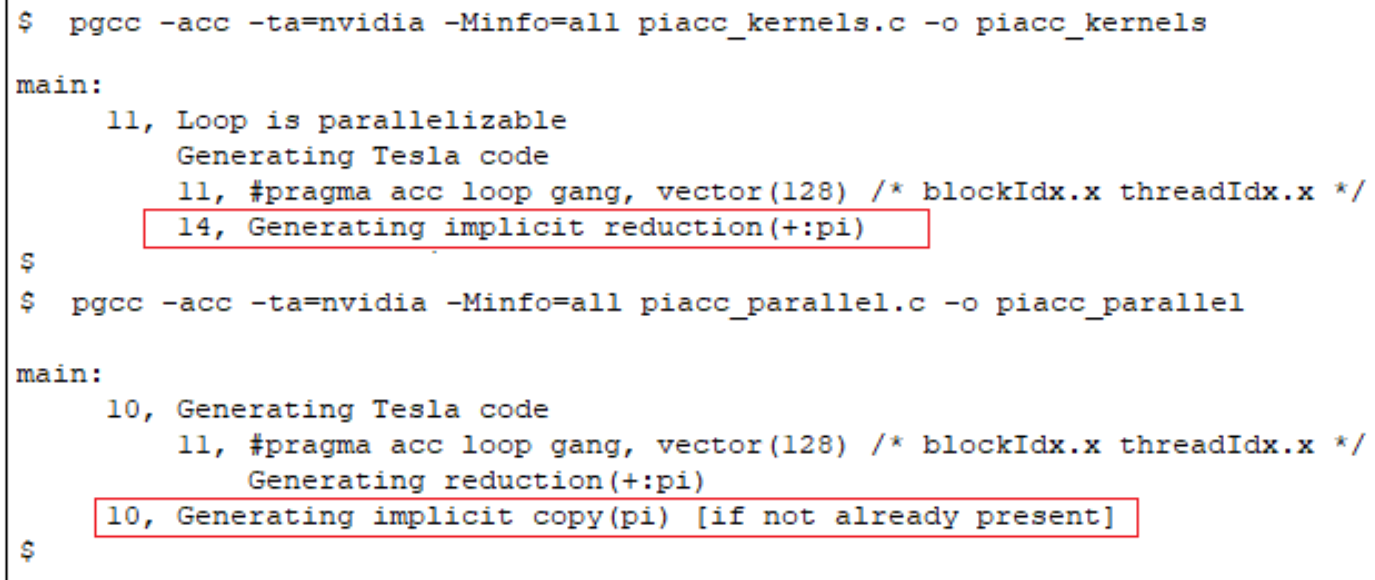

Figura 2.7: Saída do compilador PGI

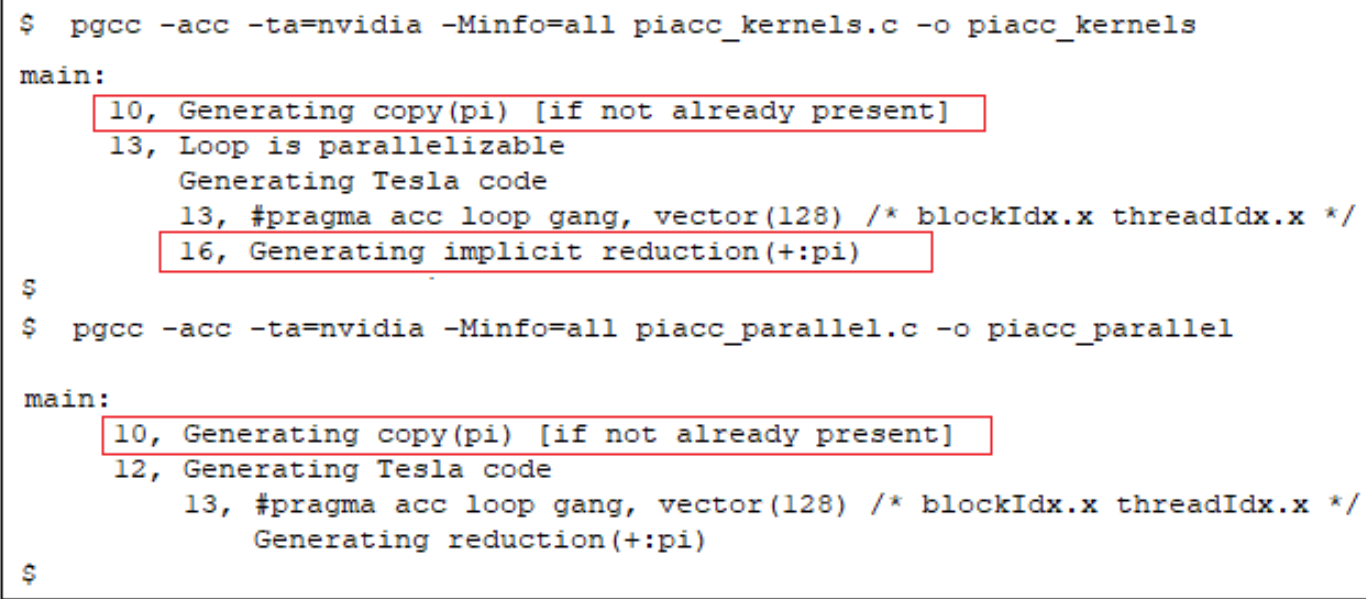

Figura 2.8: Saída do compilador PGI usando movimentação de dados

Na diretiva kernels a redução sempre é feita de forma implícita pelo compilador, mas a movimentação dos dados para o acelerador não ocorre. Por sua vez, com uso da diretiva parallel, a redução é realizada de forma explícita e a movimentação dos dados é feita de forma implícita pelo compilador.

É possível fazer a movimentação de dados explicitamente para o acelerador usando a diretiva data. Deve-se então adicionar a linha \#pragma acc data copy(pi) antes do laço, de modo que seja feita a cópia da variável pi para a memória do acelerador. Desse modo, todo o cálculo da variável pi é realizado no acelerador (Figura 2.8).

Em alguns casos, o uso de movimentação de dados do hospedeiro para o acelerador pode ser mais lento por conta custo computacional. Neste exemplo, o tempo gasto em movimentar os dados para o acelerador não compensa devido ao baixo custo computacional do 
kernel, sendo mais eficiente realizar esses cálculos no hospedeiro. Na Figura 2.9 e Figura 2.10 os tempos de execução usando a movimentação de dados são maiores tanto com a diretiva kernels como com a diretiva parallel.

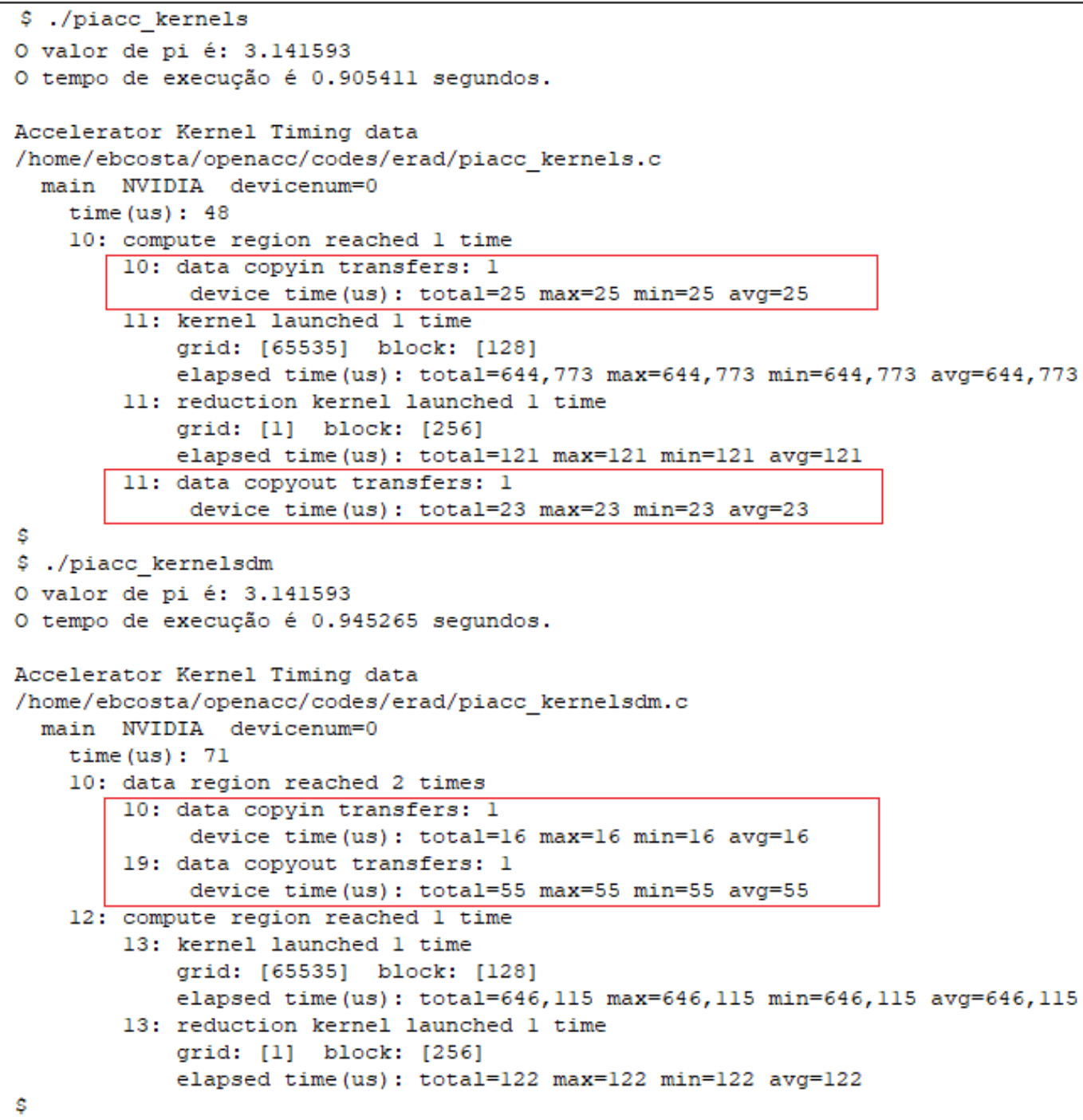

Figura 2.9: Tempo de execução usando movimentação de dados com a diretiva kernels 


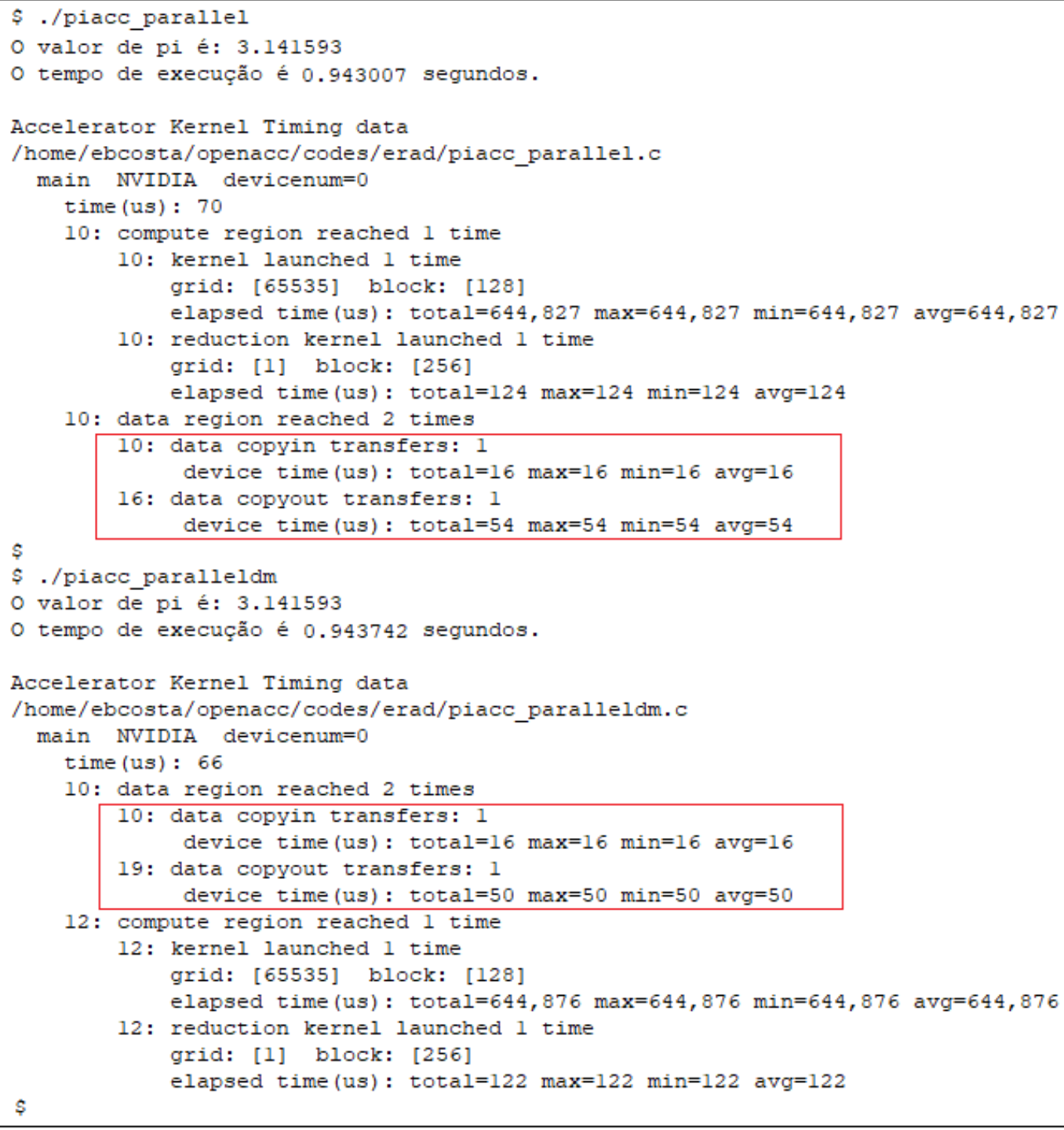

Figura 2.10: Tempo de execução usando movimentação de dados com a diretiva parallel

Para medir os tempos de execução dos diferentes códigos, variou-se o valor de $N$. Os valores de $N$ usados para as medições foram entre $1,0 \times 10^{9}$ a $1,5 \times 10^{10}$. Na Tabela 2.3, são apresentados os resultados obtidos para o tempo de processamento.

\begin{tabular}{|c|c|c|c|c|}
\hline Tamanho de N & kernels & kernels+data & parallel & parallel+data \\
\hline $1,0 \times 10^{9}$ & 0,305284 & 0,344658 & 0,343664 & 0,343403 \\
\hline $2,0 \times 10^{9}$ & 0,346696 & 0,384993 & 0,384135 & 0,385037 \\
\hline $1,0 \times 10^{10}$ & 0,688010 & 0,723660 & 0,723909 & 0,728856 \\
\hline $1,5 \times 10^{10}$ & 0,905921 & 0,943896 & 0,944225 & 0,944746 \\
\hline
\end{tabular}

Tabela 2.3: Uso de recursos do acelerador

Nas Figura 2.11 e Figura 2.12, são apresentadas as análises do comportamento do cálculo 
de Pi com uso do pgprof com o uso de ambas diretivas, com movimentação de dados (diretiva data). Como visto anteriormente, o comportamento é o mesmo independente da diretiva utilizada.

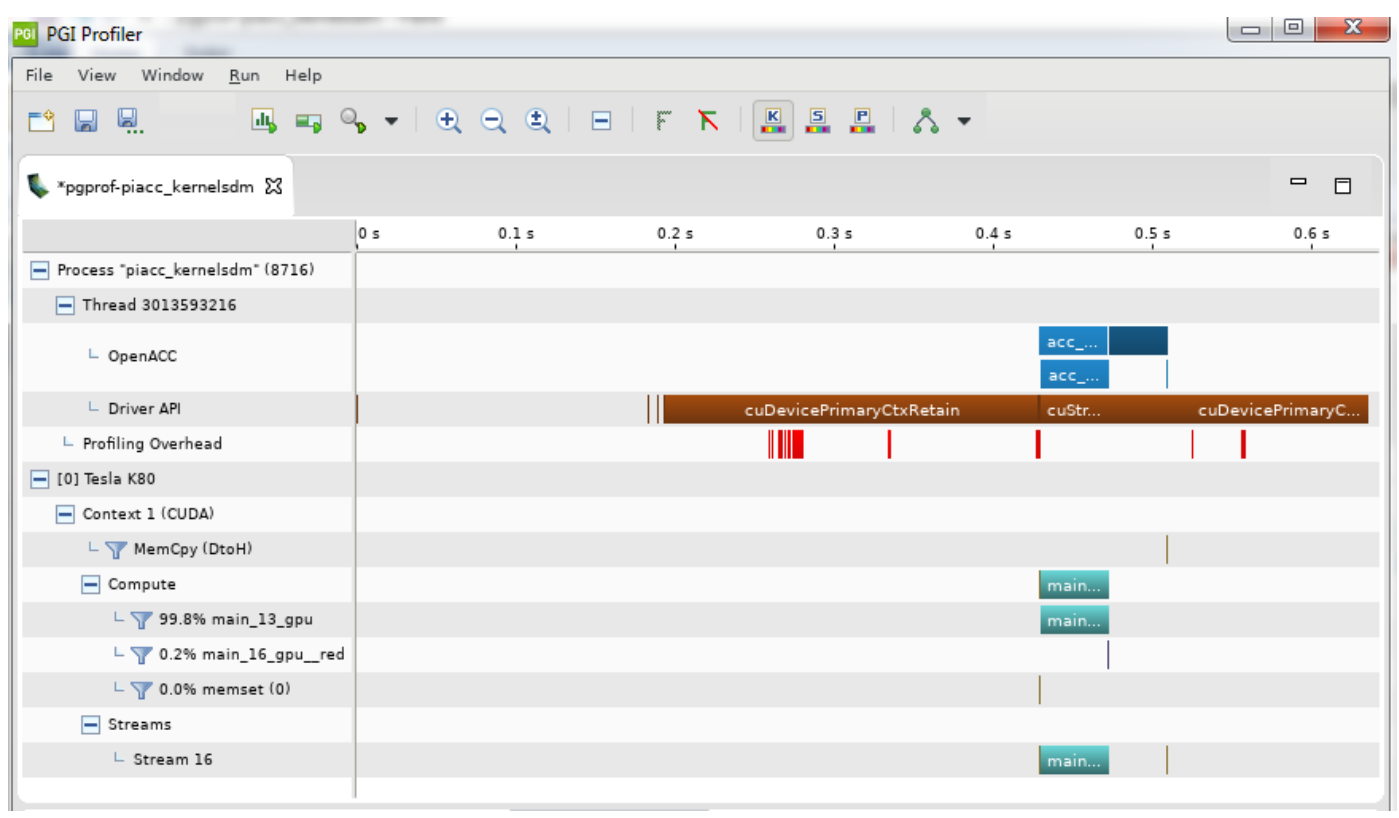

Figura 2.11: Análise de execução do código usando a diretiva kernels com movimentação de dados

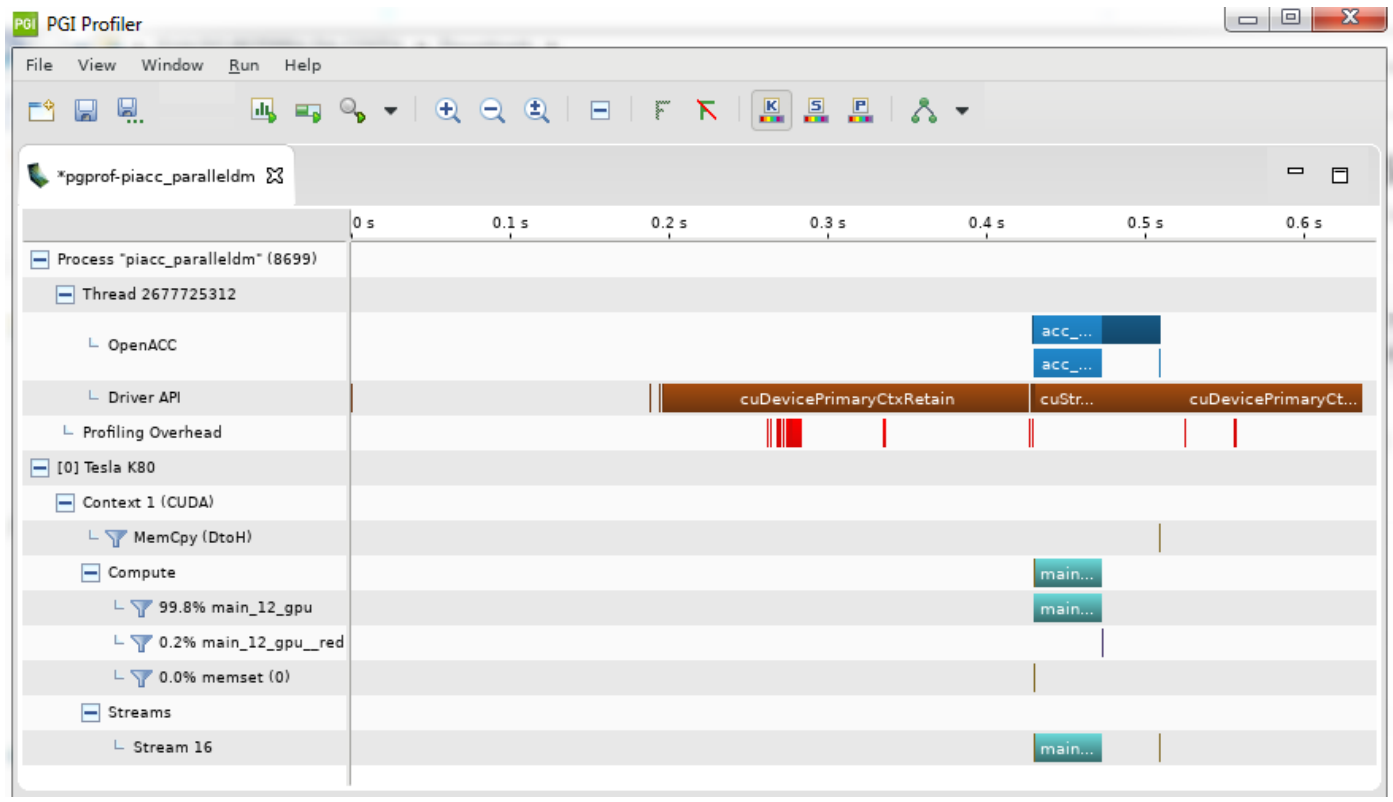

Figura 2.12: Análise de execução do código usando a diretiva parallel com movimentação de dados 


\subsubsection{Método Jacobi}

O Método de Jacobi é um procedimento iterativo para a resolução de sistemas lineares. Converge iterativamente para o valor correto, calculando novos valores em cada ponto a partir da média dos pontos vizinhos. Neste exemplo faremos o cálculo da temperatura na placa usando a equação de Laplace: $\nabla^{2} f(x, y)=0$.

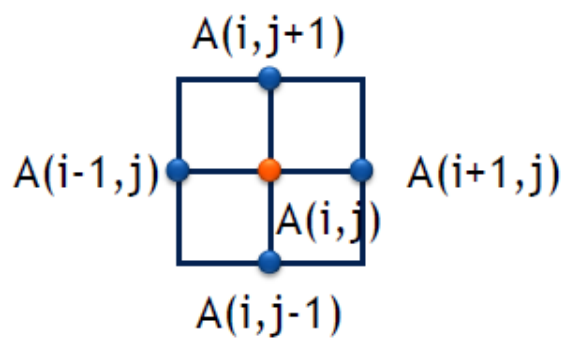

$$
A_{k+1}(i, j)=\frac{A_{k}(i-1, j)+A_{k}(i+1, j)+A_{k}(i, j-1)+A_{k}(i, j+1)}{4}
$$

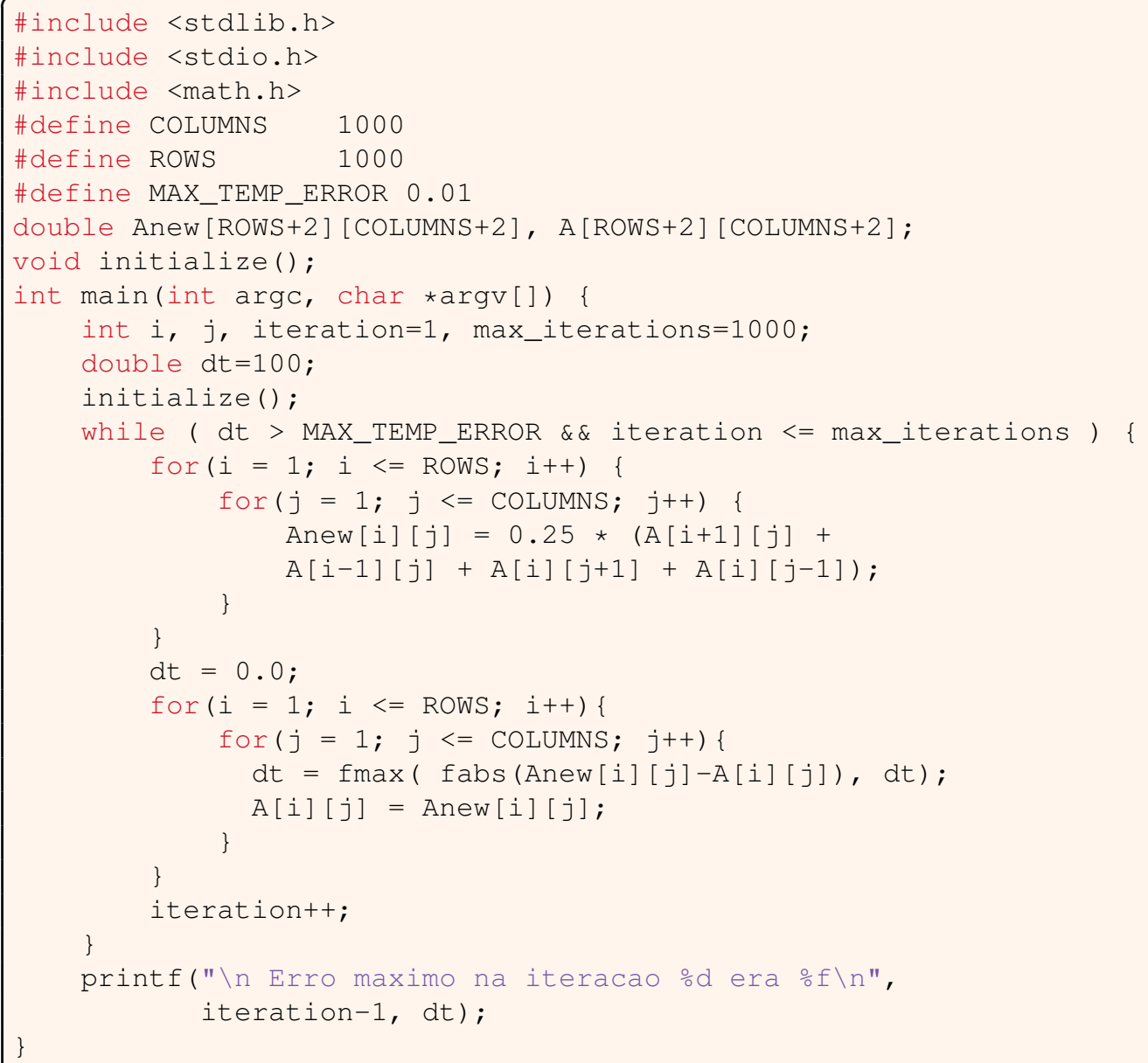

Exemplo 2.7: Método de Jacobi Sequencial 
Como pode ser visto no código sequencial (Exemplo 2.7), o primeiro laço dentro do while de convergência calcula o novo valor para cada elemento com base nos valores atuais de seus vizinhos, cujo resultado é armazenado em uma matriz temporária Anew. Isso garante que todos os valores sejam calculados usando o estado atual de $\mathbf{A}$ antes que o conteúdo de A seja novamente atualizado. Como resultado, cada iteração do laço é completamente independente da outra.

Esse laço também calcula um máximo valor de erro. O valor do erro é a máxima diferença de temperatura entre o novo valor e o antigo. Se o erro entre duas iterações estiver dentro de alguma tolerância, o problema será considerado como convergido e o laço externo será encerrado. O segundo laço simplesmente atualiza o valor de $\mathbf{A}$ com os valores calculados em Anew.

Para que o cálculo seja executado pelo acelerador usaremos a diretiva parallel do OpenACC. Adicionar a linha antes do primeiro laço:

\section{\#pragma acc parallel loop}

E a linha:

\section{\#pragma acc parallel loop reduction(max:dt)}

Antes do segundo laço, como visto a seguir.

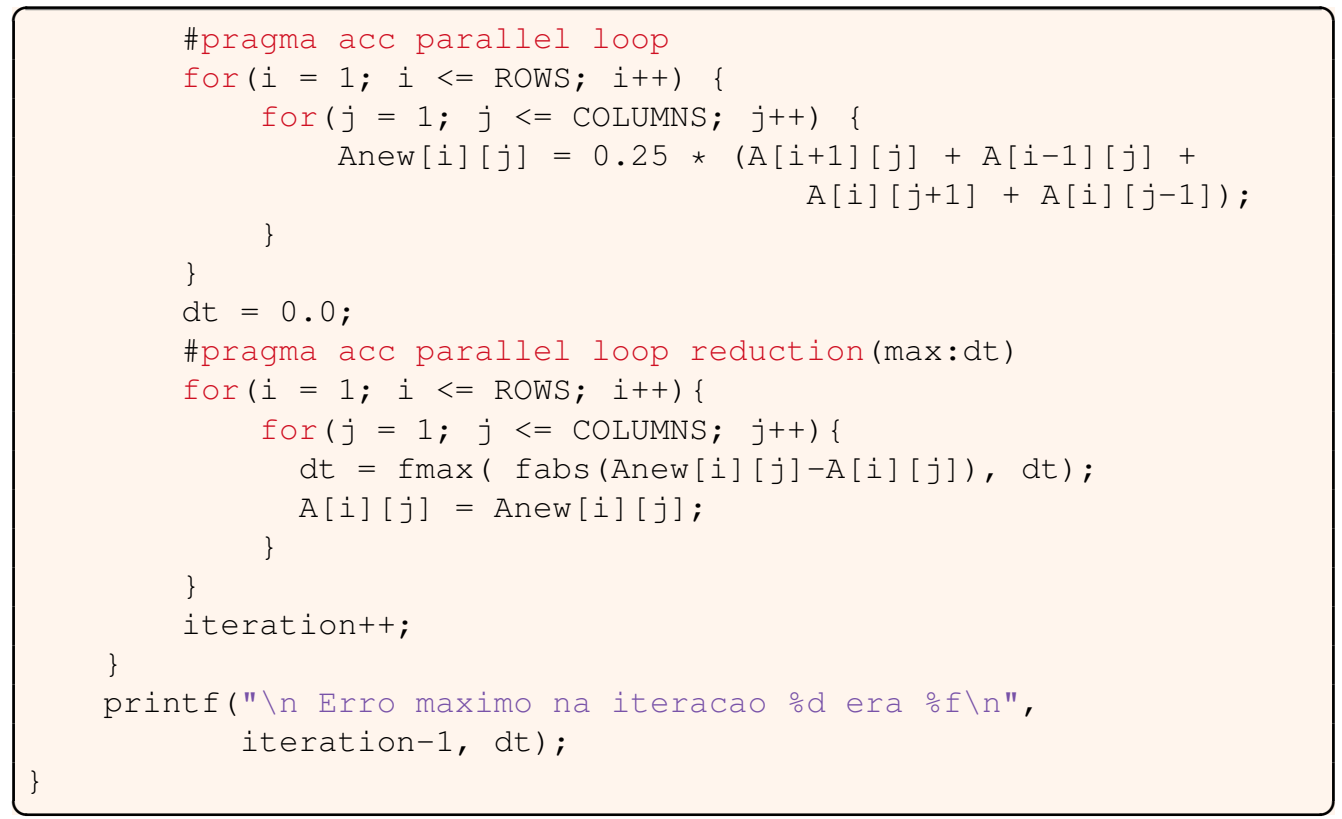

Na Figura 2.13 vemos a saída do compilador PGI. A movimentação dos dados para o acelerador é realizada de forma automática pelo compilador. Desse modo a matriz de cálculo não está armazenada no acelerador. Toda vez que o acelerador executa uma operação, as informações são gravadas na matriz que está na memória do hospedeiro. Esta operação tem um alto custo computacional, tornando a execução do código lenta (Figura 2.14). 


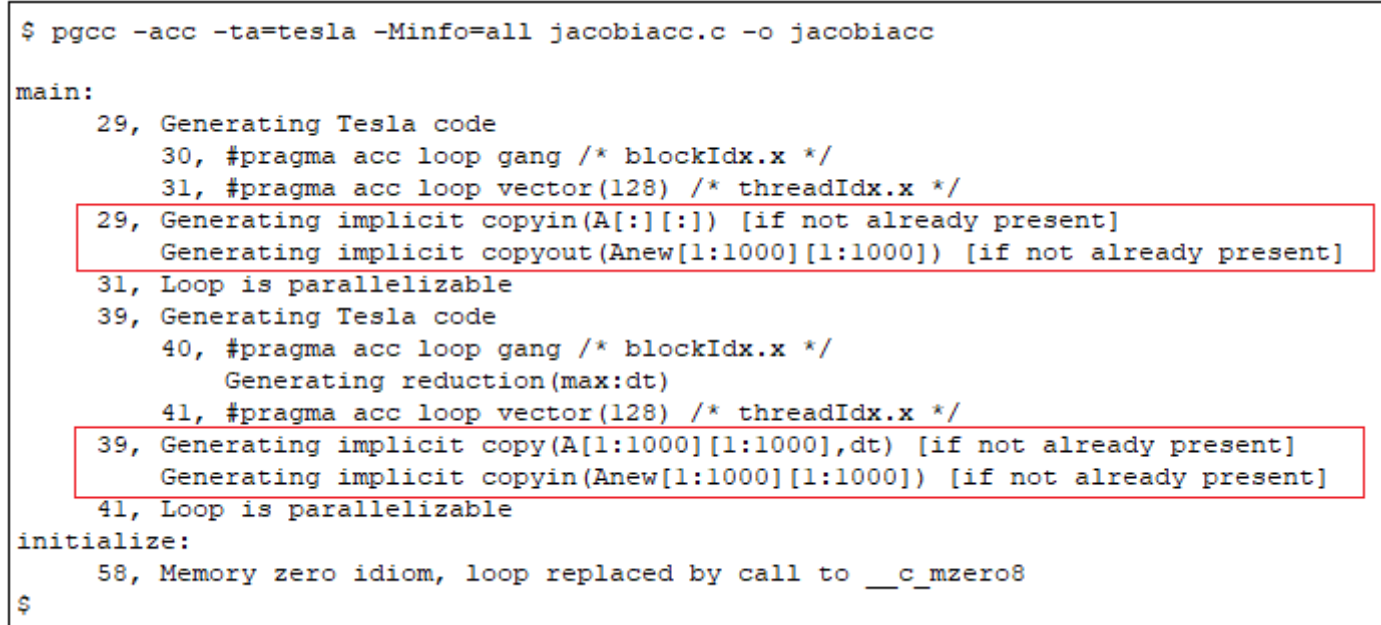

Figura 2.13: Saída do compilador PGI sem uso de movimentação de dados

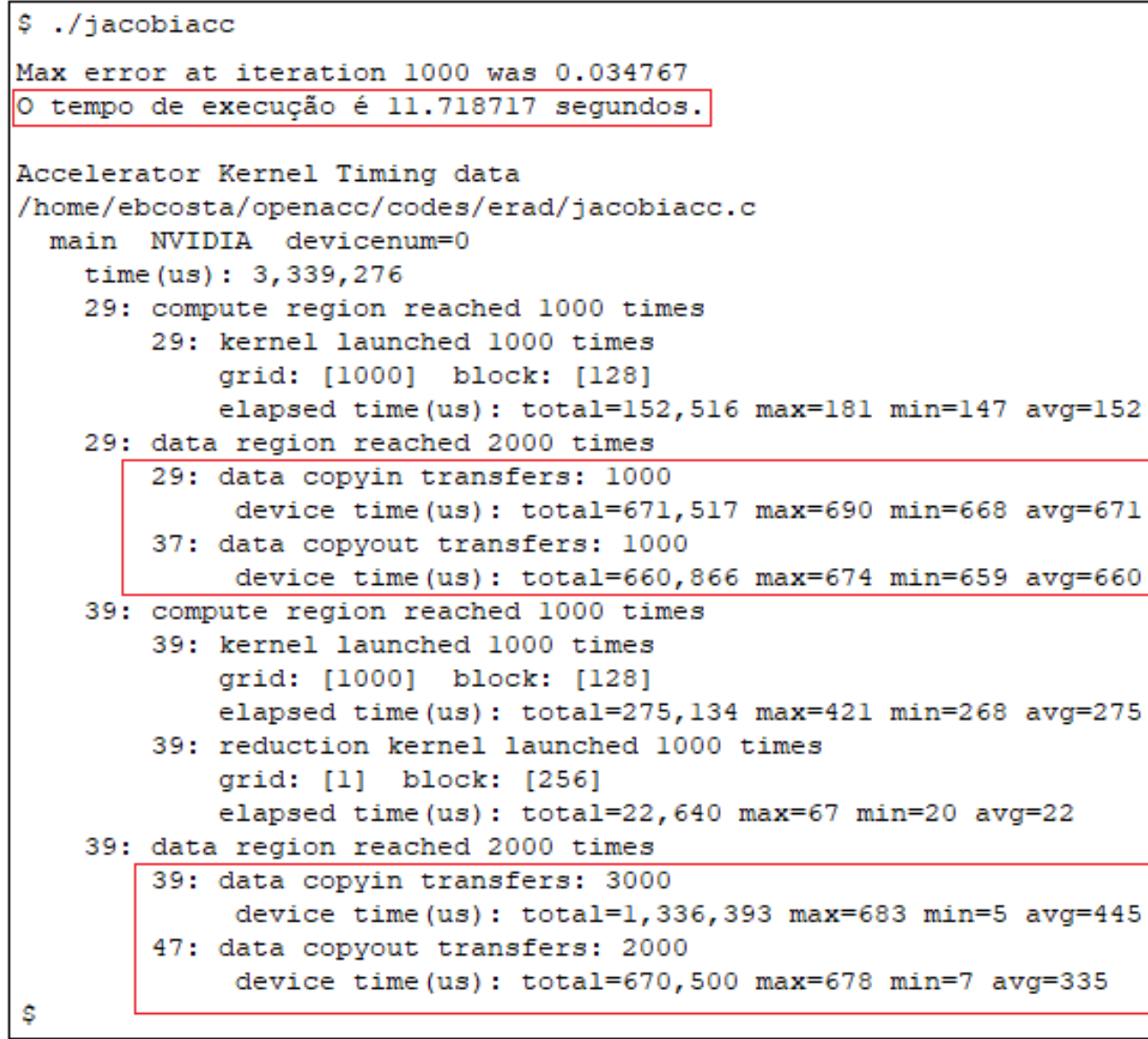

Figura 2.14: Tempo de execução sem uso de movimentação de dados

Para resolver esse problema é necessário informar ao compilador que uma cópia da matriz A deve ser feita para o acelerador no início da região paralela. Desse modo, não será 
mais necessário gravar as informações no hospedeiro toda vez que for realizada uma operação de escrita na matriz pelo acelerador. Adicionalmente, a matriz Anew será criada exclusivamente no acelerador. Usaremos a diretiva data do OpenACC para realizar essas operações. Deve-se então adicionar a linha antes dos dois laços:

\section{\#pragma acc data copy(A) create (Anew)}

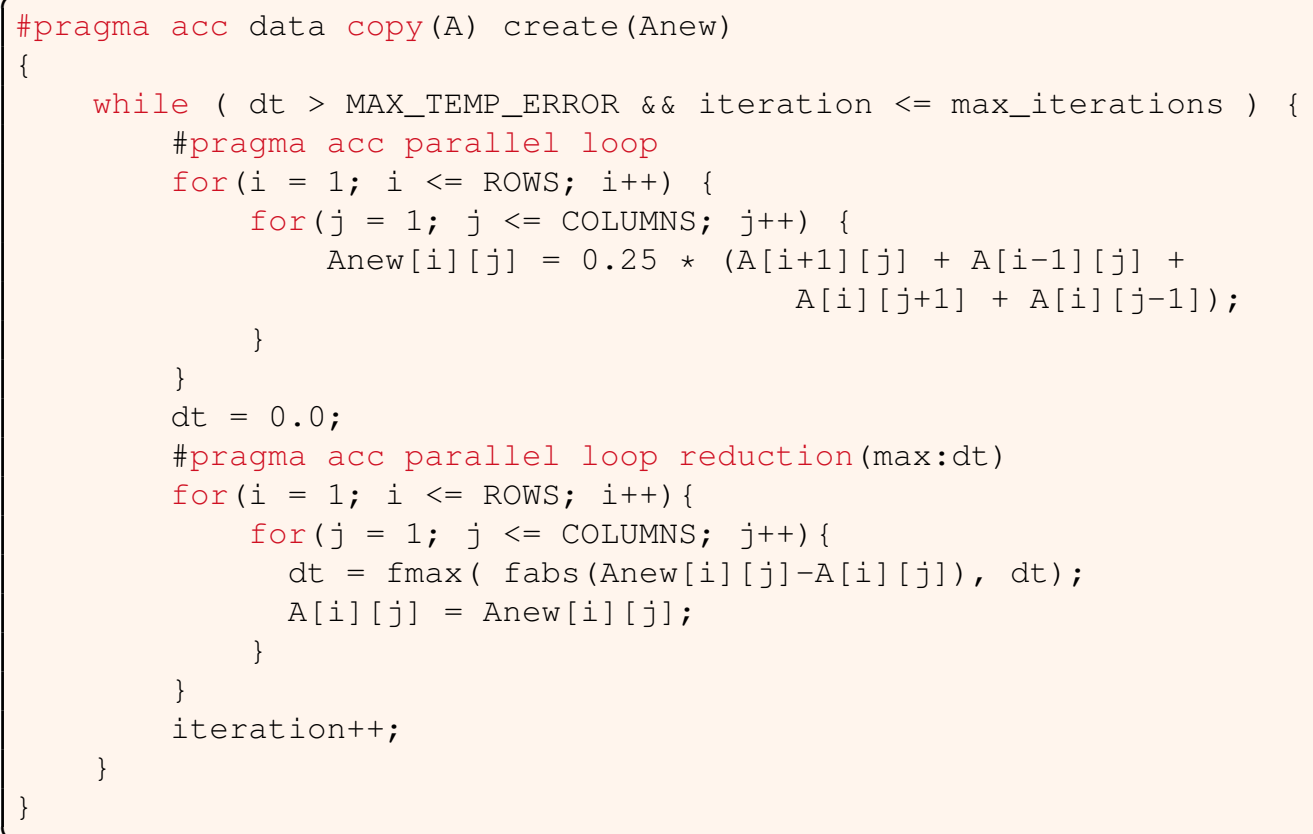

Agora todas os acessos às matrizes A e Anew serão realizados exclusivamente no acelerador, com isto, não haverá custo adicional de acesso aos dados na memória do hospedeiro para o cálculo da matriz (Figura 2.15).

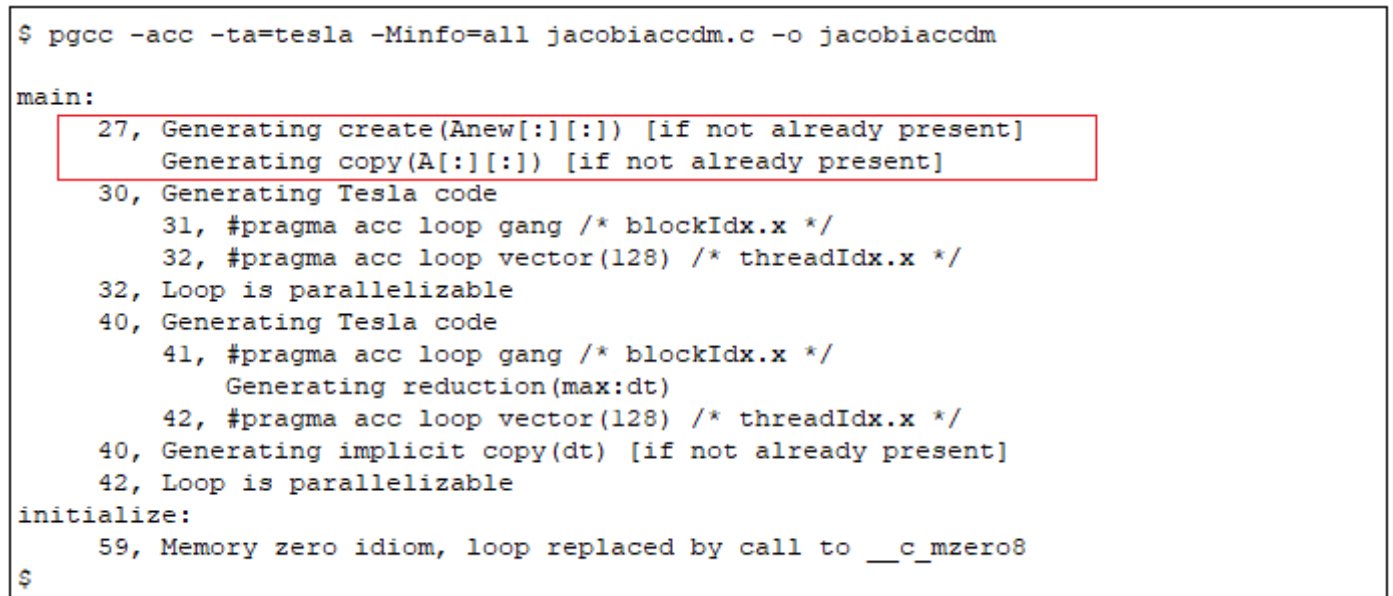

Figura 2.15: Saída com do compilador PGI usando movimentação de dados

O tempo total gasto para a execução sem a movimentação de dados foi de 11,71 segundos. 
Usando a movimentação de dados o tempo total passou para 0,80 segundos, ou seja, 14,62 vezes mais rápido. Este é um exemplo onde o uso de movimentação de dados propicia ganhos consideráveis (Figura 2.16).

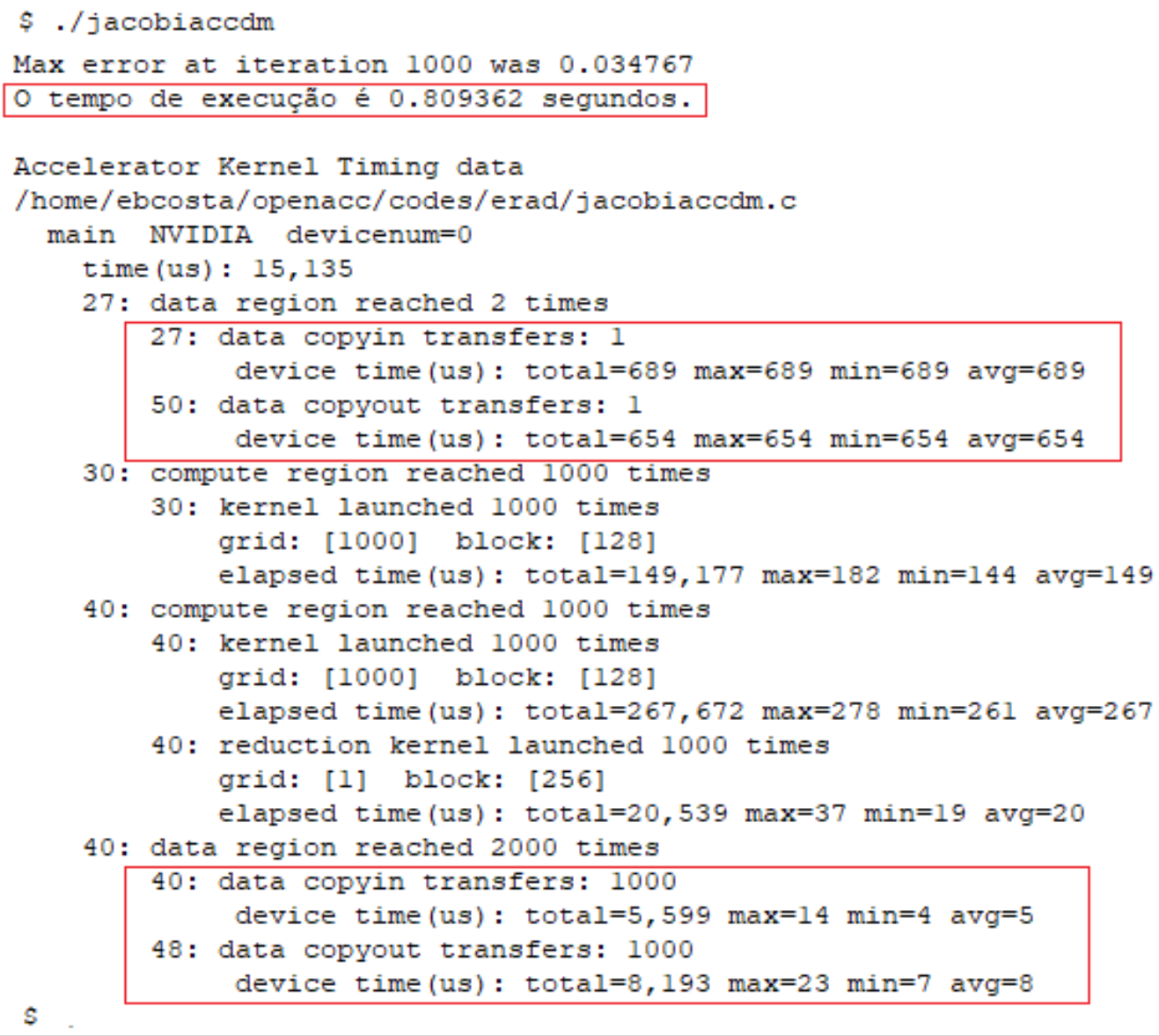

Figura 2.16: Tempo de execução usando movimentação de dados

As Figuras 2.17 e 2.18 apresentam os resultados gerados usando o pgprof. Na Figura 2.17 a análise do código foi realizada sem movimentação de dados e a Figura $2.18 \mathrm{com}$ a movimentação de dados para o acelerador.

Nota-se que o tempo e o custo computacional são maiores quando não é feita a movimentação de dados, visto que toda vez que se faz uma operação na matriz, existe a necessidade do acelerador fazer o acesso aos dados no hospedeiro. Quando a matriz é movimentada de forma definitiva para o acelerador, esse custo computacional é muito menor.

\subsubsection{Cálculo do fractal de Mandelbrot}

Os fractais são figuras geométricas complexas que apresentam como característica principal a autossimilaridade. O fractal de Mandelbrot é um fractal definido como o conjunto de pontos $\mathrm{C}$ no plano complexo. O conjunto de Mandelbrot é obtido quando submetemos 


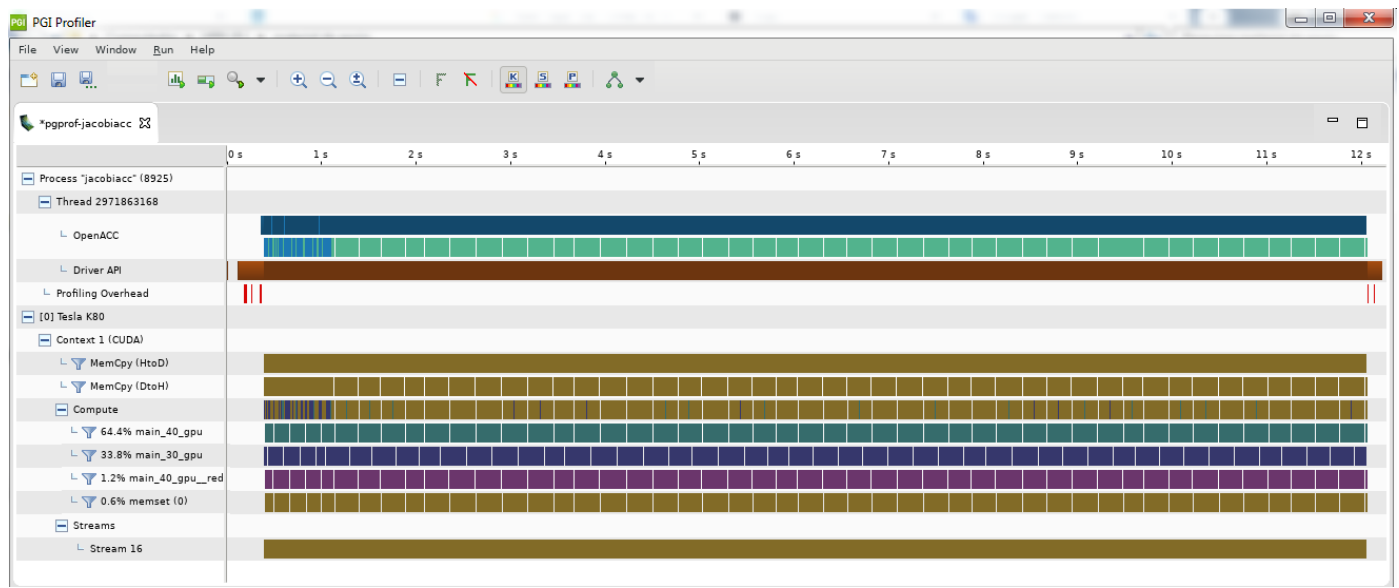

Figura 2.17: Análise de execução do código sem uso de movimentação de dados

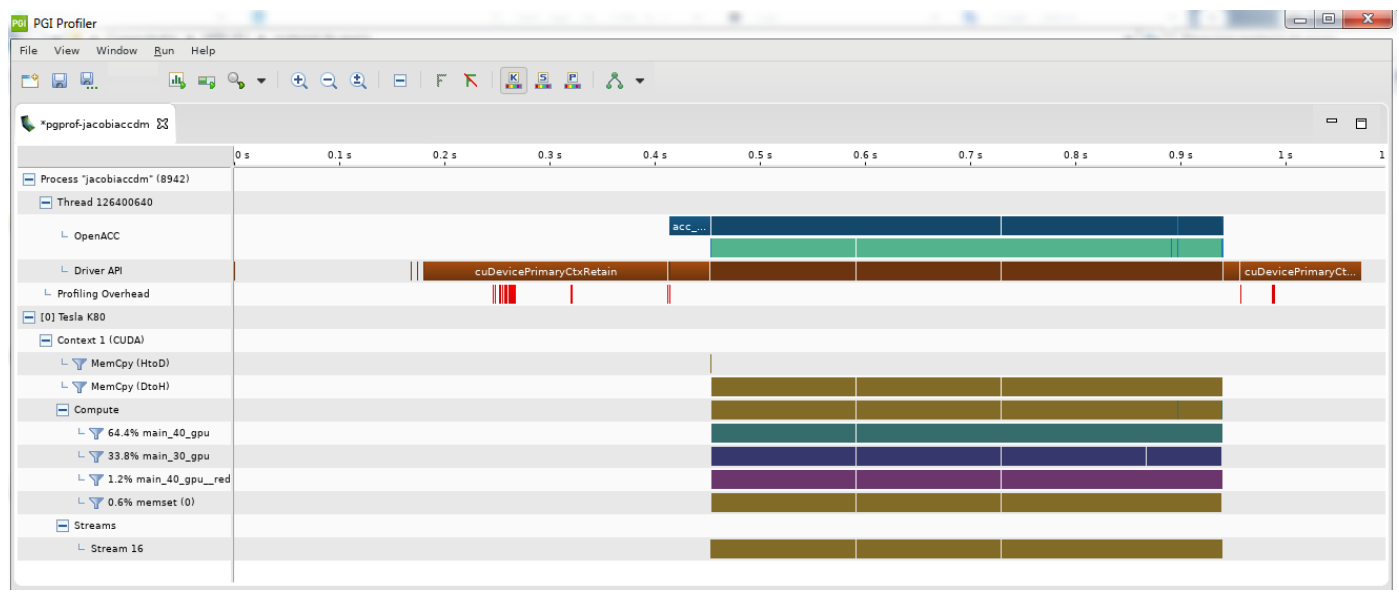

Figura 2.18: Análise de execução do código usando movimentação de dados

os números complexos a um processo iterativo e recursivo utilizando a fórmula:

$$
Z_{n+1}=Z_{n}^{2}+C
$$

A execução do fractal de Mandelbrot dentro do laço na versão sequencial (Exemplo 2.8) será feito por uma thread, independente da quantidade de processadores que existam no sistema (Figura 2.19). 


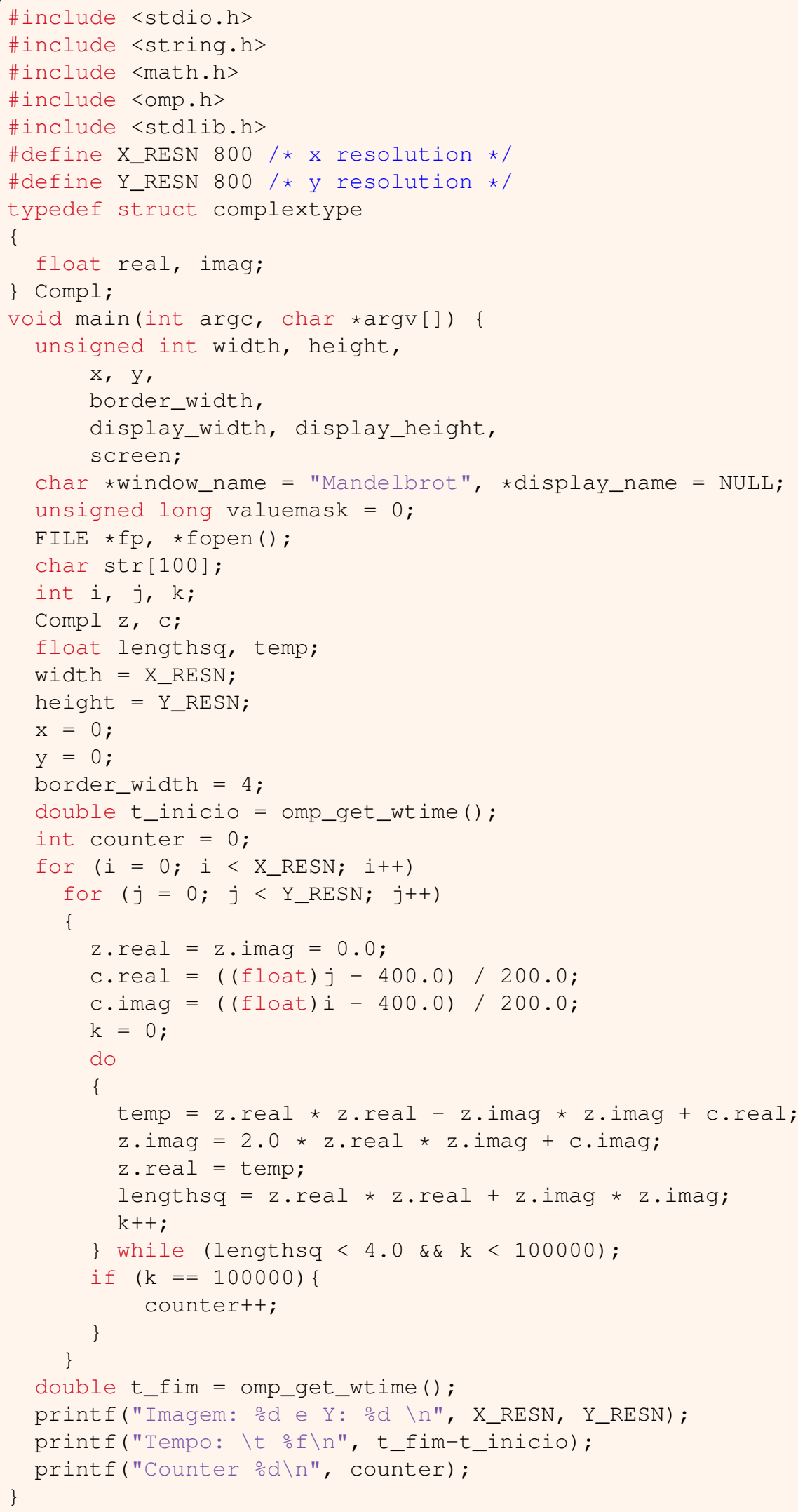

Exemplo 2.8: Mandelbrot Sequencial 


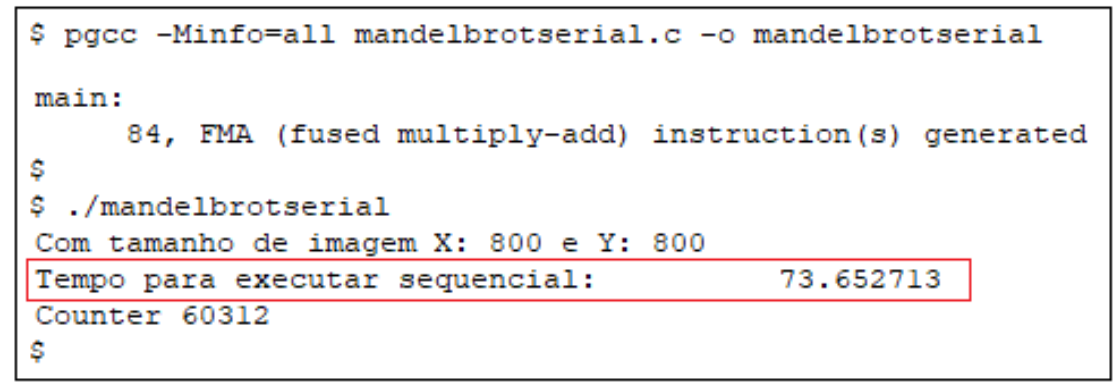

Figura 2.19: Compilação Mandelbrot sequencial e tempo de execução

O tempo total para a execução sequencial foi de 73,65 segundos. Para a versão em OpenACC (Figura 2.20), usaremos inicialmente a diretiva parallel adicionando a linha:

\section{\#pragma acc parallel loop copy}

\#pragma acc parallel loop copy(counter)

for $\left(i=0 ; i<X \_R E S N ; i++\right)$

for $\left(j=0 ; j<Y \_R E S N ; j++\right)$

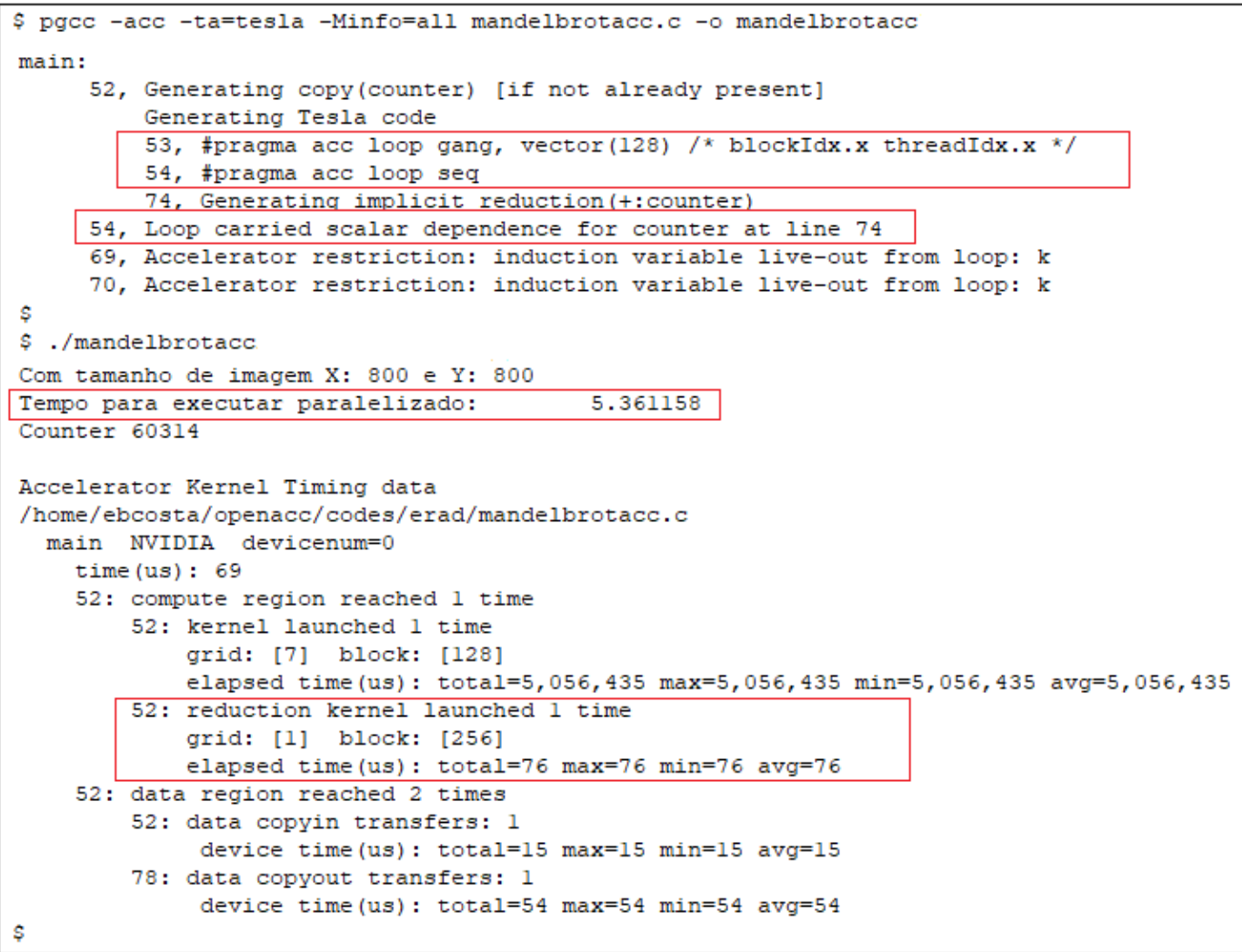

Figura 2.20: Compilação do código usando OpenACC e o tempo de execução

Embora esta versão do código usando OpenACC tenha um tempo de execução de 5,36 
segundos, sendo 13,74 vezes mais rápido que a versão sequencial, podemos melhorar o código usando outras diretivas. O tempo de execução pode ainda ser diminuído com o uso da diretiva atomic:

\section{\#pragma acc atomic update}

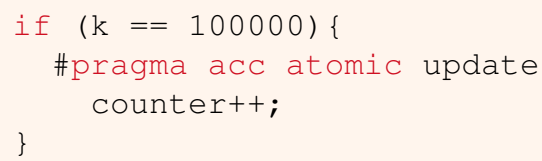

Com o uso dessa diretiva o tempo de execução passou para 0,40 segundos. Nessa nova versão do código o tempo de execução foi 13,40 vezes mais rápido em comparação de primeira versão do OpenACC e 184,12 mais rápido vezes em comparação a versão sequencial (Figura 2.21).

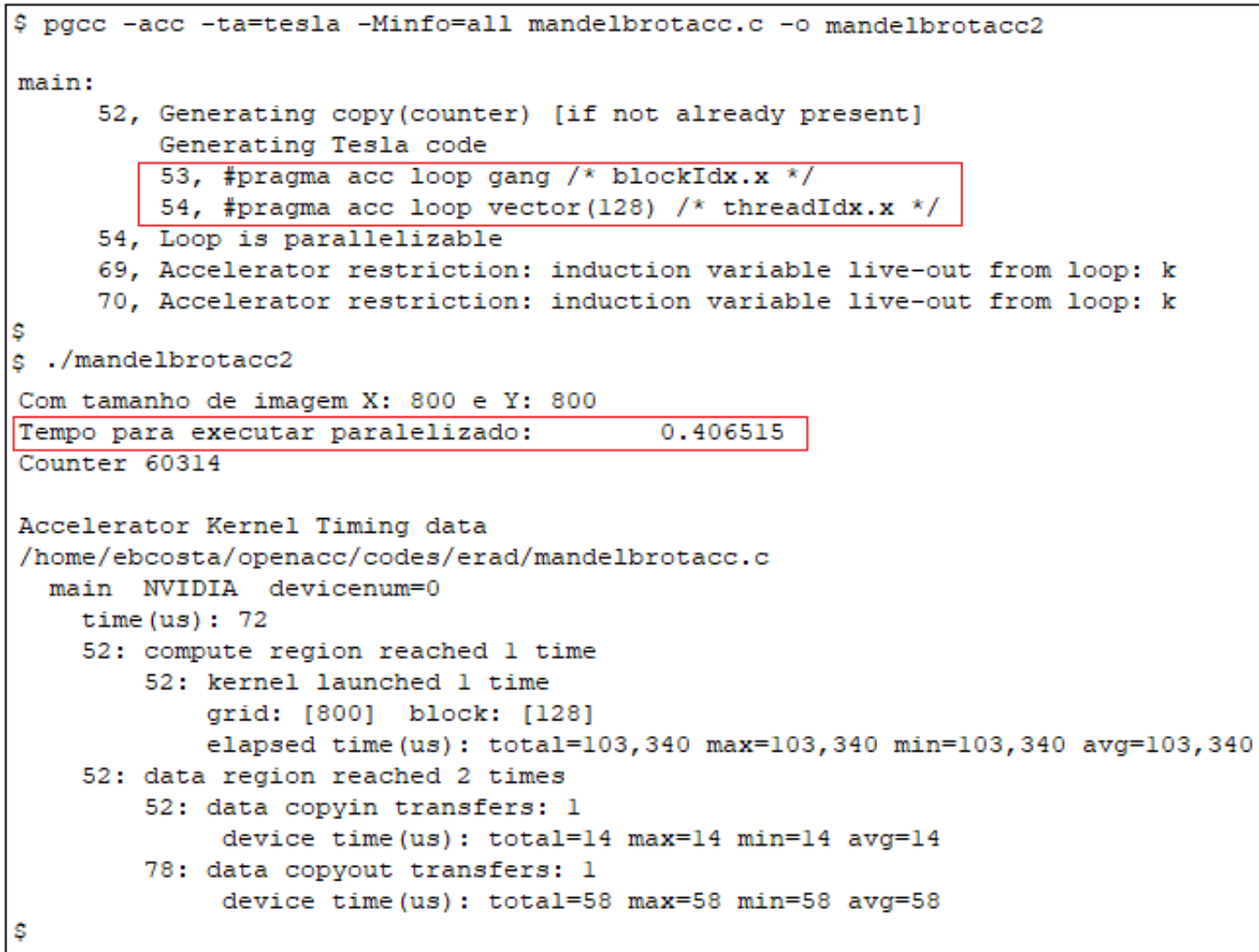

Figura 2.21: Compilação do código usando a diretiva atomic e o tempo de execução

O uso da diretiva parallel e a movimentação de dados obteve um ganho significativo em relação a versão sequencial (Figura 2.22). Porém, quando foi feito o uso da diretiva atomic, esse ganho foi muito superior a versão sequencial (Figura 2.23). 


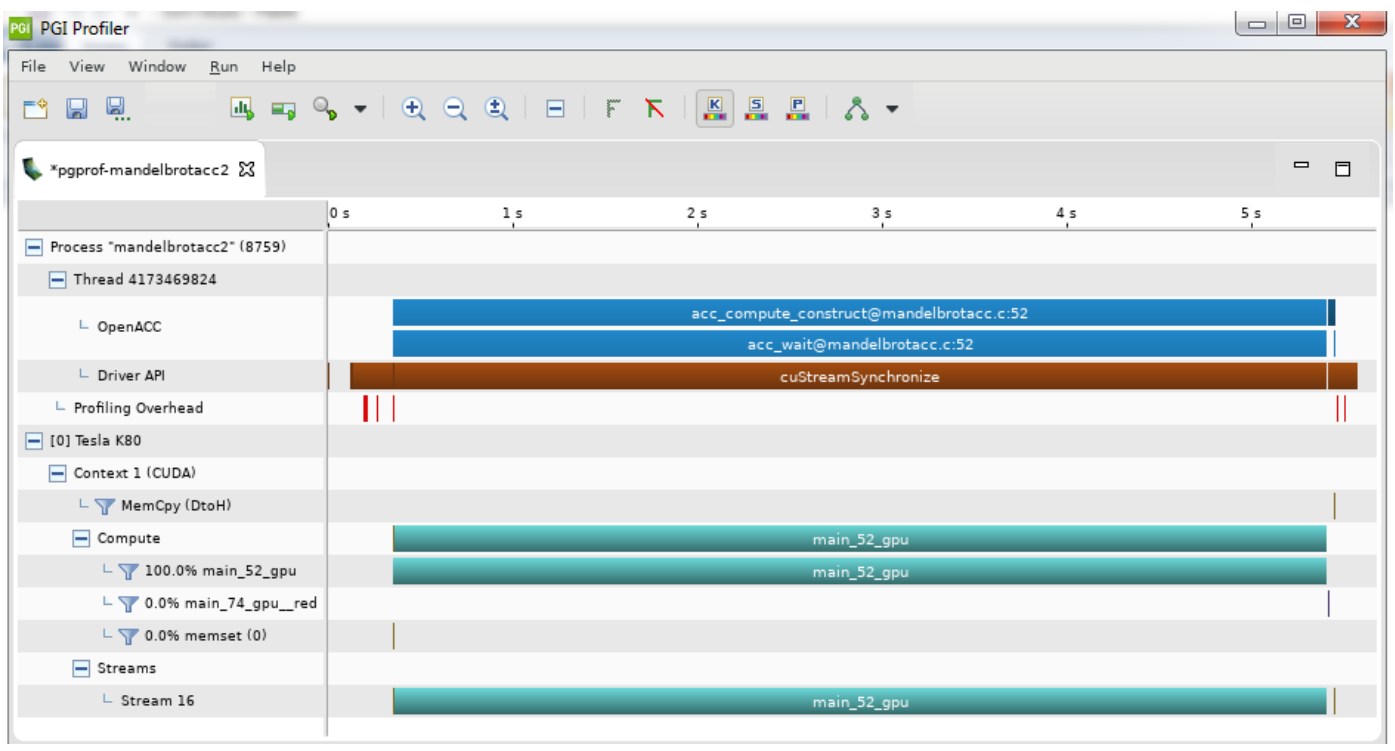

Figura 2.22: Análise de execução do código usando movimentação de dados

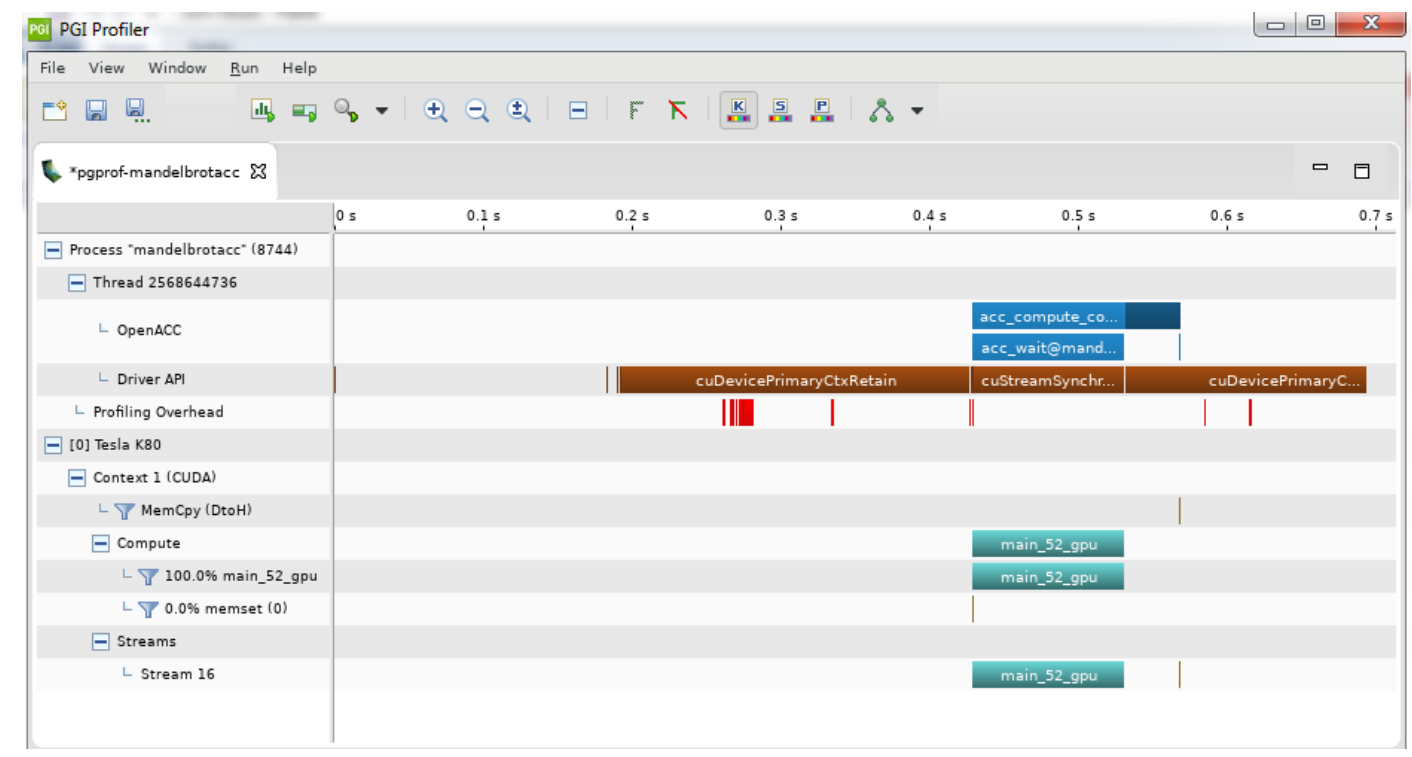

Figura 2.23: Análise de execução do código usando movimentação de dados e a diretiva atomic

\subsubsection{Cálculo de números primos}

O código do Exemplo 2.9 calcula a quantidade de números primos entre 0 e um determinado valor inteiro $\mathrm{N}$. Este programa basicamente verifica se $\mathrm{N}$ é divisível por algum número ímpar entre 0 e a raiz quadrada de $\mathrm{N}$, sendo que os números pares são descartados de imediato. 


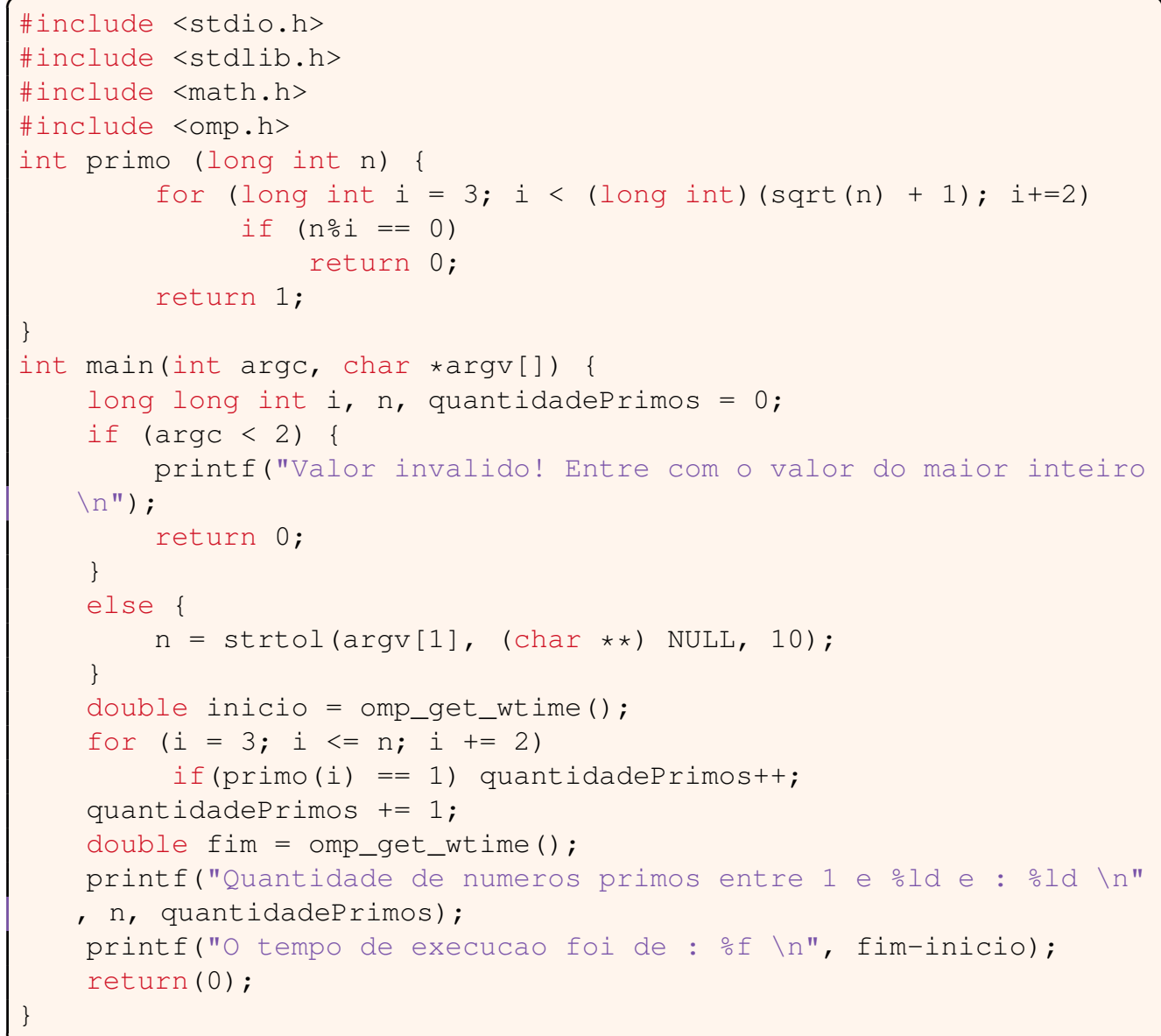

Exemplo 2.9: Primos Sequencial

Na Figura 2.24 pode ser vista a compilação do código e o tempo total para a execução sequencial, que foi de 16,12 segundos. Para a versão em OpenACC, primeiramente usaremos as diretivas routine e parallel dentro da rotina primo(). Para o uso da diretiva routine adicionar a linha:

\section{\#pragma acc routine}

Antes de iniciar a rotina e a linha:

\section{\#pragma acc loop}

Antes do primeiro laço para calcular a raiz quadrada.

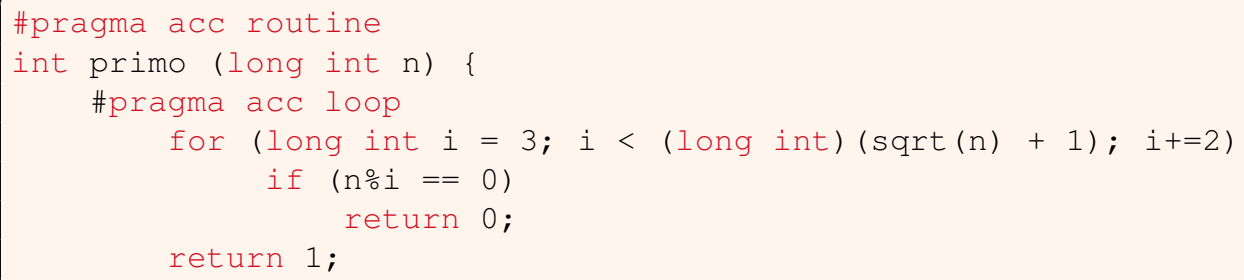




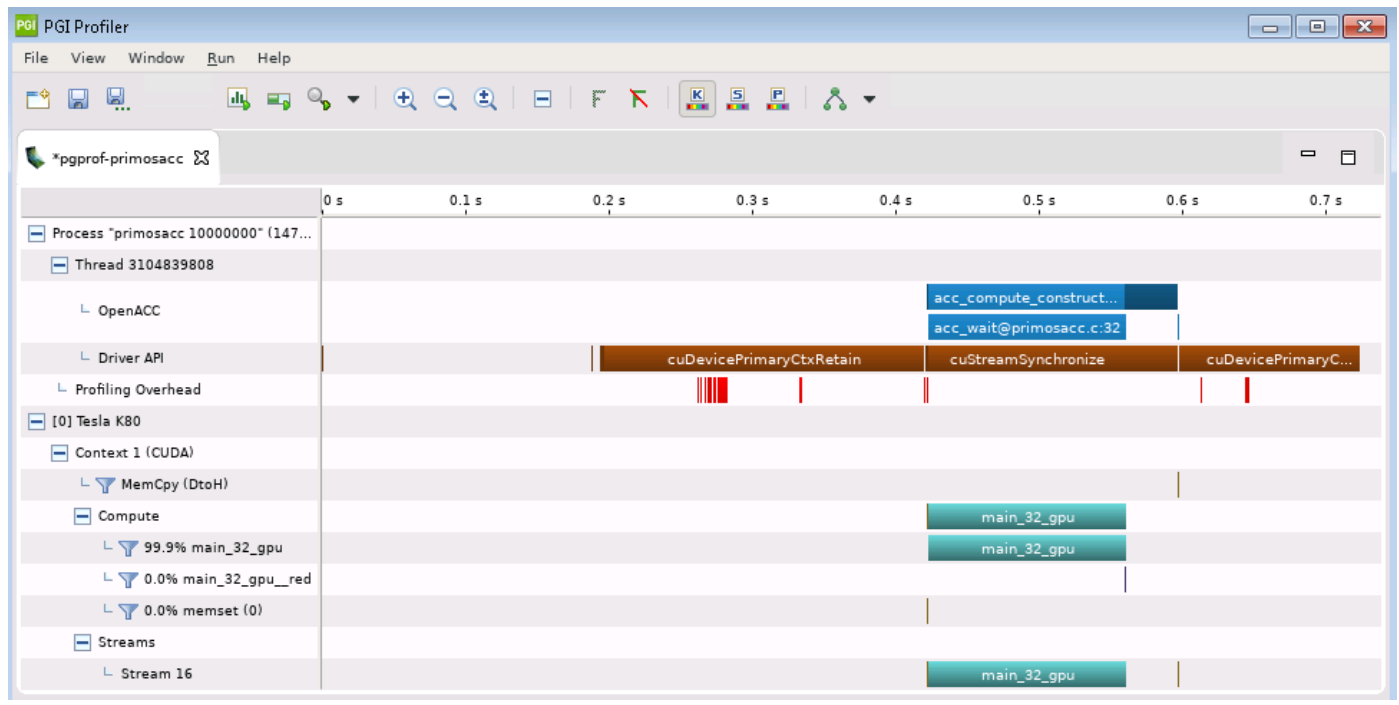

Figura 2.26: Análise de execução do código usando as diretiva Routine e parallel

A Figura 2.26 apresenta a análise da execução do código para o cálculo de números primos usando as diretivas routine e parallel utilizando o programa pgprof.

\subsubsection{Cálculo de multplicação de matrizes}

A multiplicação de matrizes corresponde ao produto entre duas matrizes. O produto de duas matrizes só é possível somente quando o número de colunas da primeira matriz é igual ao número de linhas da segunda matriz. $\mathrm{O}$ algoritmo que iremos apresentar, conhecido como "ingênuo", apresenta complexidade computacional $O(m n p)$, para a multiplicação de uma matriz $m \times n$ por outra $n \times p$, se todas as dimensões forem iguais a "n", diz-se que a complexidade é $O\left(n^{3}\right)$.

Utilizando-se álgebra linear, podem-se obter algoritmos que podem alcançar complexidades melhores, tais como o algoritmo do alemão Volker Strassen, que consegue uma complexidade de $O\left(n^{2,807}\right)$ pela redução do número de multiplicações necessárias necessárias para cada sub-matriz $2 \times 2$ de 8 para 7 .

Um outro algoritmo conhecido de multiplicação de matrizes é o Coppersmith-Winograd, com uma complexidade de $O\left(n^{2,3737}\right)$. Contudo, a menos que as matrizes sejam enormes, esses algoritmos não resultam em reduções significativas no tempo de computação.

Assim sendo, na prática, o melhor método para acelerar a multiplicação de matrizes é o uso de algoritmos paralelos, como os que iremos apresentar a seguir. Contudo, vamos apresentar primeiramente o código sequencial "ingênuo", qque pode ser visto no Exemplo 2.10. 


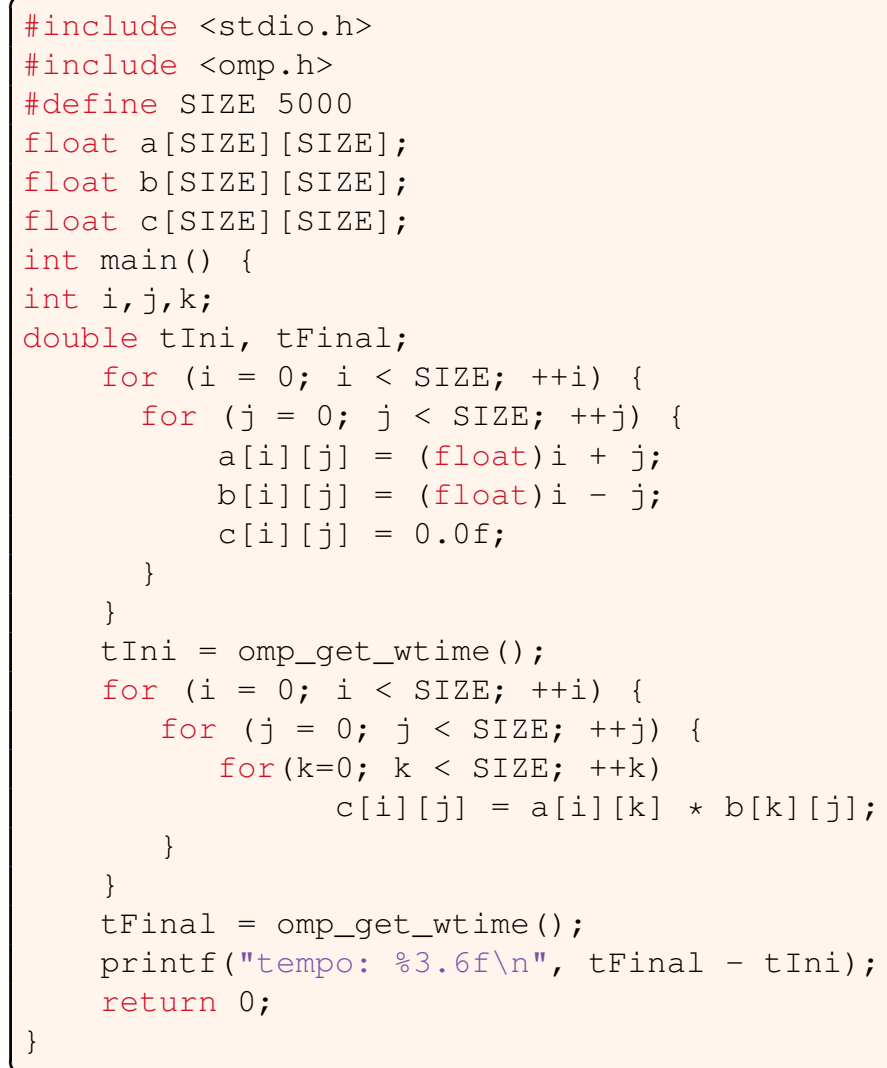

Exemplo 2.10: Multiplicação de matrizes sequencial

Esse código sequencial apresenta diversos problemas para uma implementação em OpenACC. Em primeiro lugar, deve ser feita a linearização das matrizes, para que o acesso aos dados no acelerador seja feito de uma forma mais otimizada, ou seja, em endereços sequenciais na memória.

Em segundo lugar, deve-se declarar uma variável temporária para armazenar o valor de c[i][j] que está sendo calculado no laço mais interno. Da forma que está colocada no código original, serão gerados acessos desnecessários à matriz c, independemente de ela estar armazenada na memória do hospedeiro ou do acelerador. Logo, no Exemplo 2.11 chegamos a uma versão sequencial mais adequada para trabalharmos a conversão para OpenACC. 


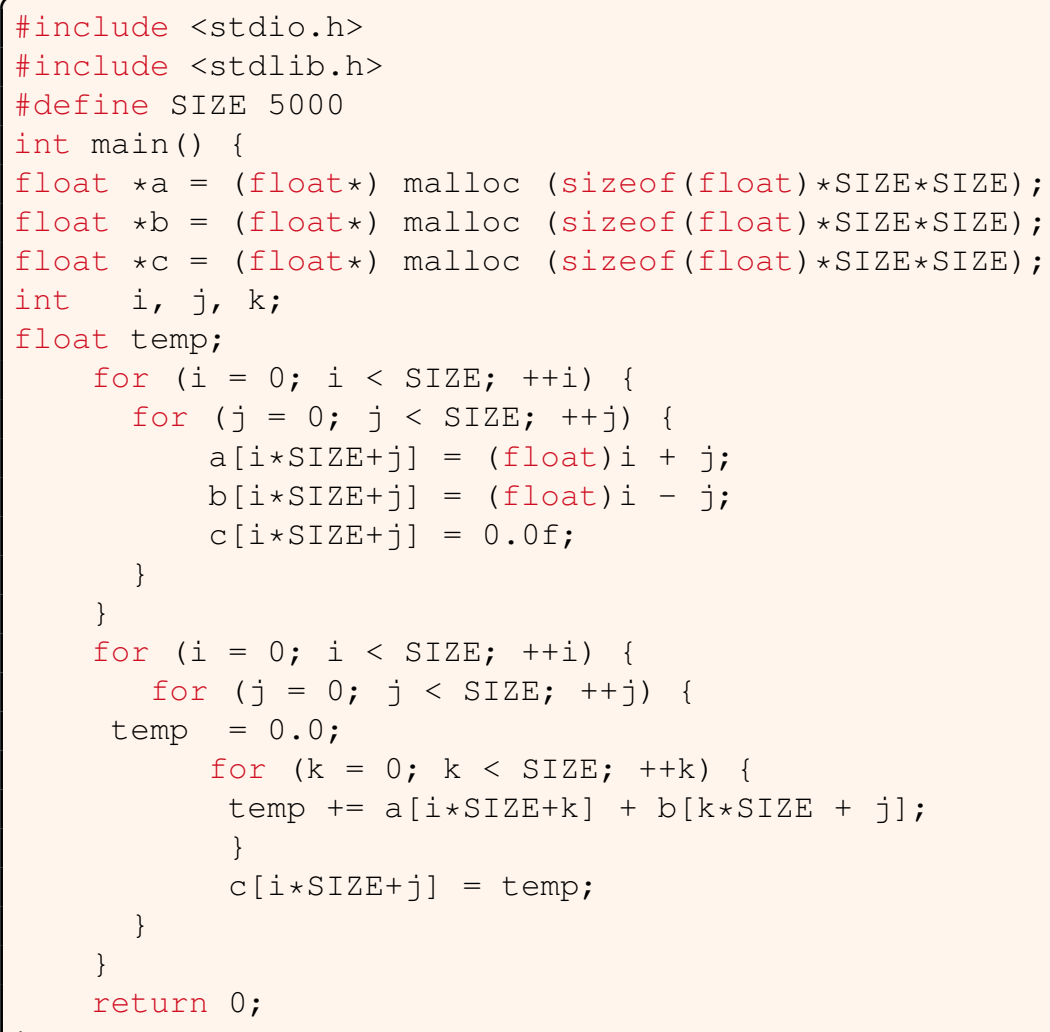

Exemplo 2.11: Multiplicação de matrizes otimizada

Para uma primeira versão em OpenACC utilizaremos a diretiva kernels e data e veremos como o compilador se comporta para realizar essa paralelização. Essa primeira versão é apresentada no Exemplo 2.12.

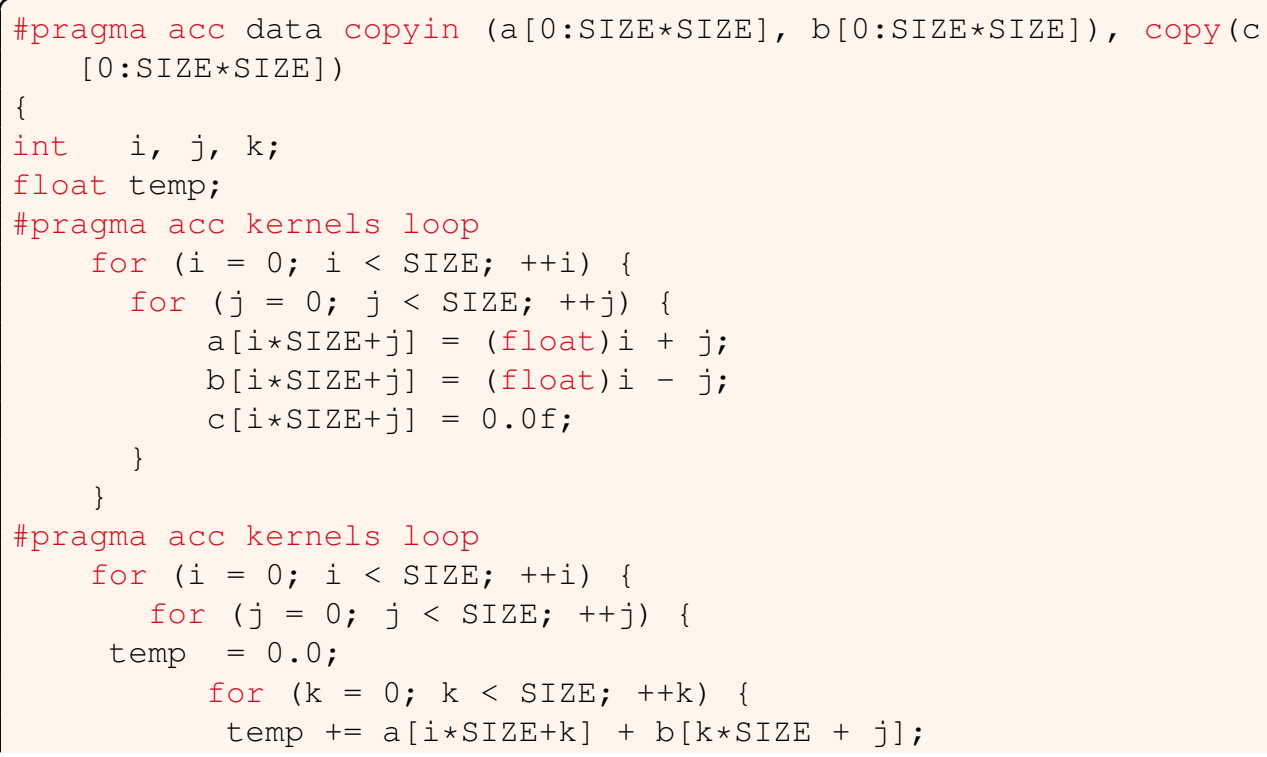




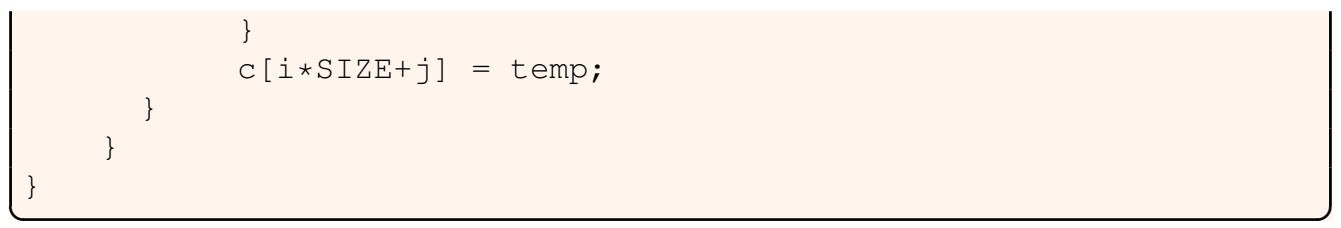

Exemplo 2.12: Multiplicação de matrizes - versão inicial OpenACC

Como podemos observar, o ganho de desempenho obtido não é tão relevante para essa versão, mesmo com os cuidados para a movimentação de dados para o acelerador e otimizações realizadas (Figura 2.27).

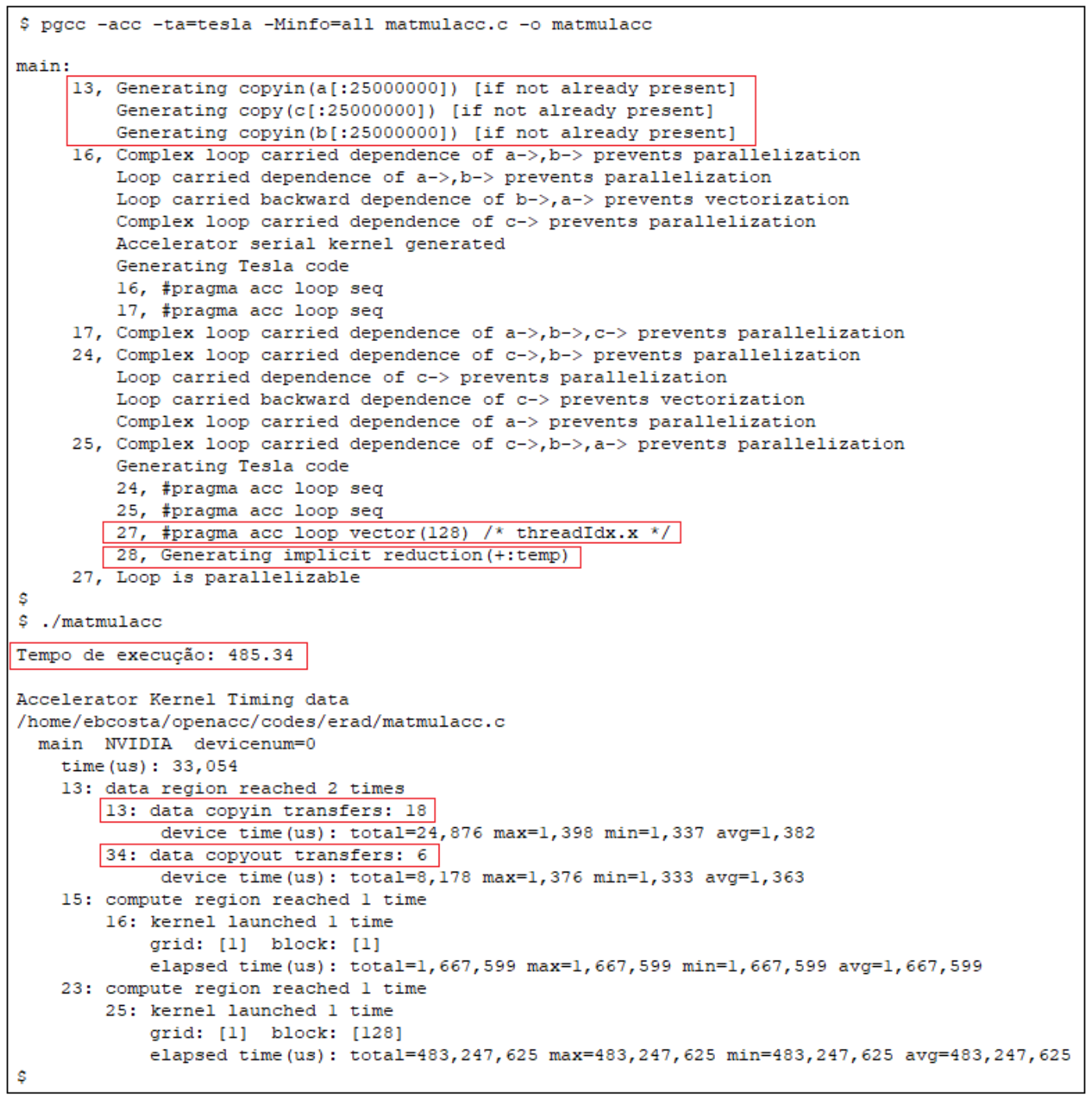

Figura 2.27: Compilação do código usando a diretiva kernels

No Exemplo 2.13 iremos fazer uso da diretiva parallel e das cláusulas reduction, collapse e tile. A diretiva que tem maior impacto é tile pelo fato de permitir o acesso otimizado 
a sub-blocos das matrizes. Esse acesso é realizado nos níveis mais altos da hierarquia do acelerador, a partir cache de nível 2, resultando em tempos de computação muito mais otimizados. Note que essa otimização só é eficiente porque o laço aninhado possui três níveis e matriz foi linearizada (Figura 2.28).

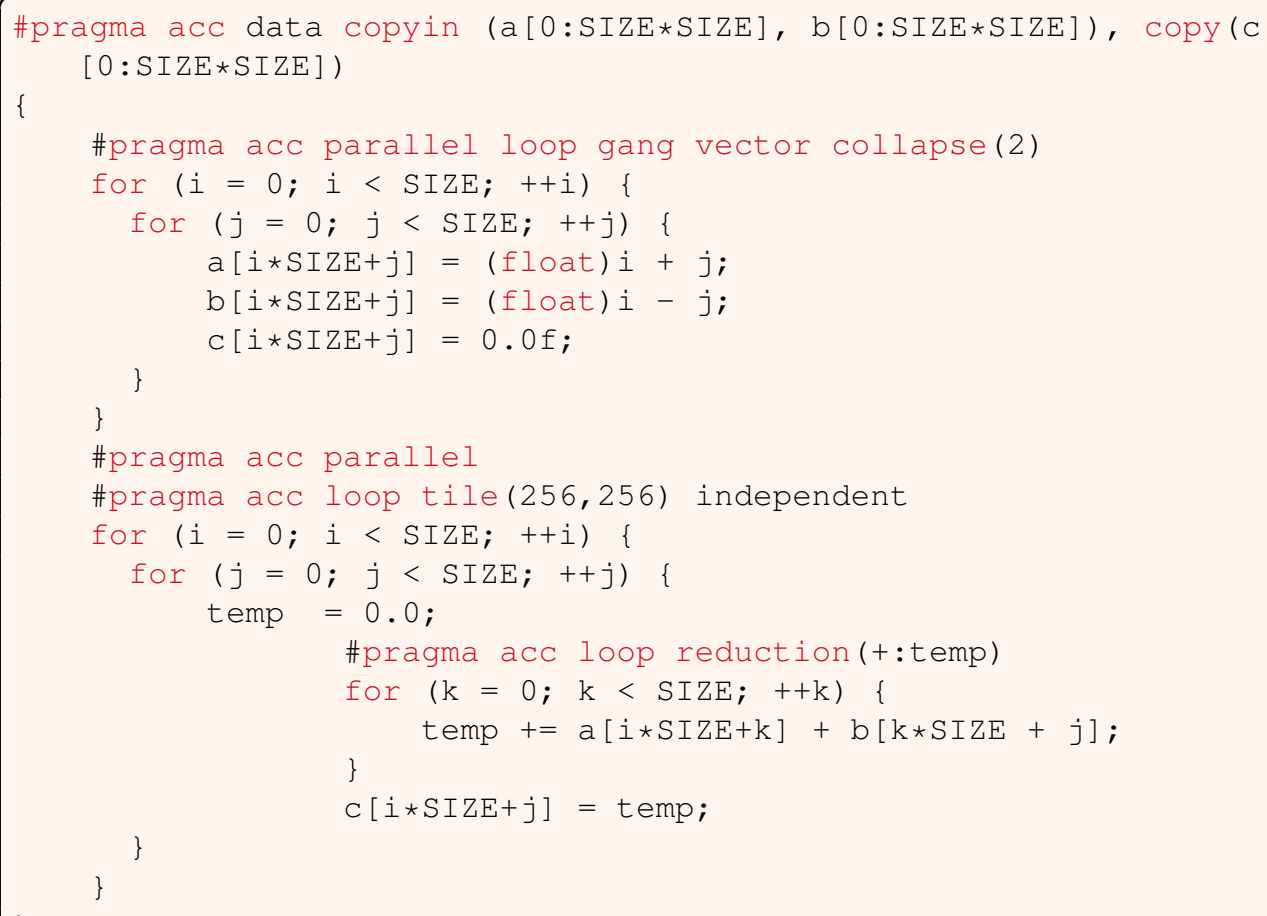

Exemplo 2.13: Multiplicação de matrizes - versão final OpenACC 


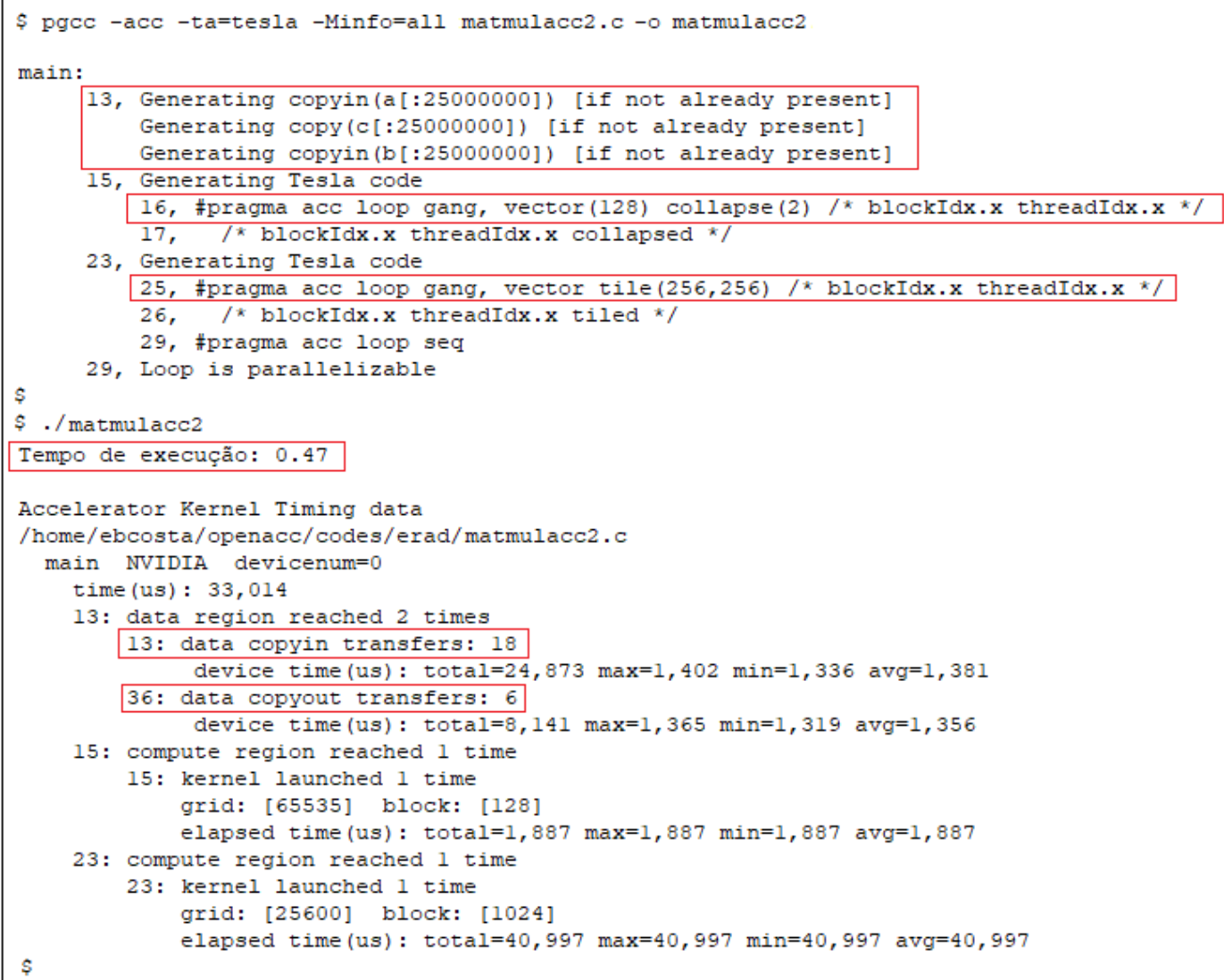

Figura 2.28: Compilação do código usando a diretiva parallel

A Figura 2.29 apresenta a análise da execução do código de multiplicação de matrizes usando a diretivas kernels, como dito anteriormente mesmo com a movimentação de dados o ganho de desempenho obtido não é tão relevante.

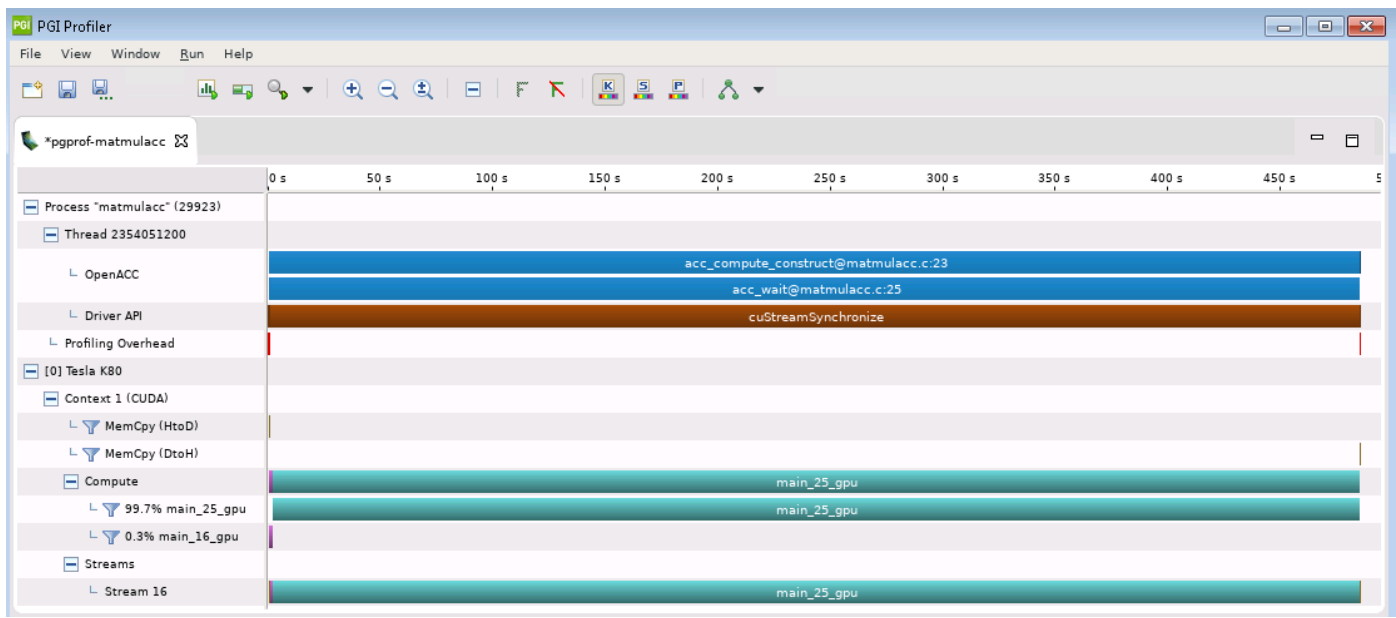

Figura 2.29: Análise de execução do código usando as diretiva data e parallel 
A Figura 2.30 apresenta a análise da execução do código de multiplicação de matrizes usando a diretivas parallel com as cláusulas collapse e tile, observa-se que o desempenho foi muito superior a versão anterior utilizando a diretiva kernels.

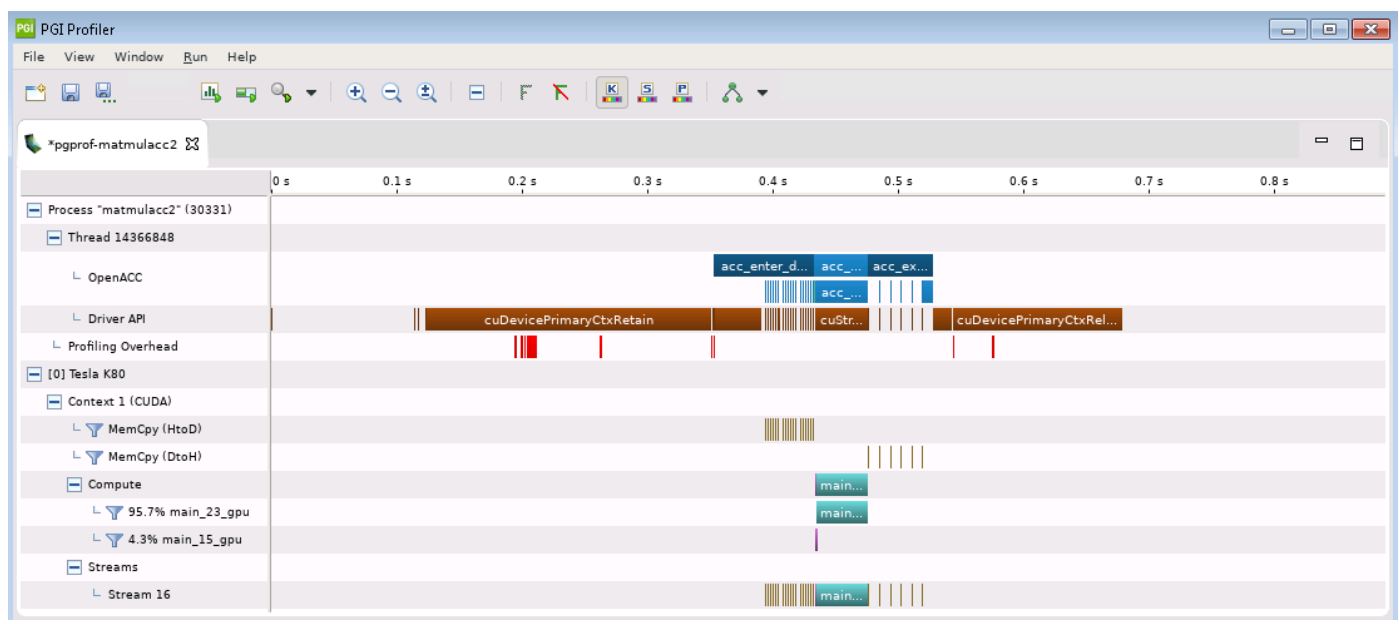

Figura 2.30: Análise de execução do código usando as diretiva data e parallel

\section{Referências}

[Chen 2017] Chen, S. (2017). Introduction to OpenACC. Research Computing Services Information Services and Technology Boston University.

[Harris 2017] Harris, M. (2017). Unified Memory for CUDA Beginners. NVIDIA Corporation.

[Murphy 2016] Murphy, J. (2016). More Tips on OpenACC Acceleration. Microway Corporation.

[NVIDIA 2014] NVIDIA (2014). NVIDIA's Next Generation CUDA Compute Architecture: Kepler TM GK110/210. NVIDIA Corporation.

[PGI 2019] PGI (2019). PROFILER USER'S GUIDE. NVIDIA Corporation. 